\title{
Interaction of the Westerlies with the Tibetan Plateau in Determining the Mei-Yu Termination
}

\author{
Wenwen Kong AND JoHn C. H. CHIANG \\ Department of Geography, and Berkeley Atmospheric Sciences Center, University of California, Berkeley, Berkeley, California
}

(Manuscript received 2 May 2019, in final form 20 September 2019)

\begin{abstract}
This study explores how the termination of the mei-yu is dynamically linked to the westerlies impinging on the Tibetan Plateau. It is found that the mei-yu stage terminates when the maximum upper-tropospheric westerlies shift beyond the northern edge of the plateau, around $40^{\circ} \mathrm{N}$. This termination is accompanied by the disappearance of tropospheric northerlies over northeastern China. The link between the transit of the jet axis across the northern edge of the plateau, the disappearance of northerlies, and termination of the mei-yu holds on a range of time scales from interannual through seasonal and pentad. Diagnostic analysis indicates that the weakening of the meridional moisture contrast and meridional wind convergence, mainly resulting from the disappearance of northerlies, causes the demise of the mei-yu front. The authors propose that the westerlies migrating north of the plateau and consequent weakening of the extratropical northerlies triggers the mei-yu termination. Model simulations are employed to test the causality between the jet and the orographic downstream northerlies by repositioning the northern edge of the plateau. As the plateau edge extends northward, orographic forcing on the westerlies strengthens, leading to persistent strong downstream northerlies and a prolonged mei-yu. Idealized simulations with a dry dynamical core further demonstrate the dynamical link between the weakening of orographically forced downstream northerlies with the positioning of the jet from south to north of the plateau. Changes in the magnitude of orographically forced stationary waves are proposed to explain why the downstream northerlies disappear when the jet axis migrates beyond the northern edge of the plateau.
\end{abstract}

\section{Introduction}

The mei-yu (also known as changma in Korea and baiu in Japan) is a quasi-stationary rain belt extending from central eastern China to Japan, establishing around midJune and disappearing around mid-July. The dynamics of the mei-yu are intimately tied to the westerlies impinging on the Tibetan Plateau. In particular, the synchronous relationship between the latitudinal position of westerlies over the Tibetan Plateau and the spatial pattern of the East Asian summer rain belt has long been recognized (Liang and Wang 1998; Molnar et al. 2010; Murakami 1951; Schiemann et al. 2009; Staff Members 1958; Yeh et al. 1959). For example, Schiemann et al. (2009) note that the westerly jet migrates onto the Tibetan Plateau in May, corresponding to the pre-mei-yu in southeastern China; the westerly jet reaches the northern edge of the plateau in June, timed to the mei-yu over central eastern

\footnotetext{
Corresponding author: Wenwen Kong, wenwen.kong@berkeley. edu
}

China; as the jet migrates well north of the plateau in July-August, midsummer occurs and brings more rainfall over northeastern China. Decreased summer rains over the Yangtze River Valley-the region dominated by the mei-yu-have been argued to be associated with the poleward displacement of westerlies in East Asia, and vice versa (e.g., Li and Zhang 2014). Recent studies further suggest that the meridional positioning of the Asian westerly jet relative to the Tibetan Plateau controls the timing and duration of the mei-yu in both past (Chiang et al. 2015; Kong et al. 2017) and present (Chiang et al. 2017) climates.

A variety of mechanisms have been proposed for how the westerlies modulate the mei-yu. Japanese meteorologists noted that the demise of the baiu is associated with the establishment of an anticyclone over Japan around August, the latter being part of an eastward propagating wave train-the so-called Silk Road pattern (Enomoto et al. 2003). Subsequent studies suggest that the interannual variation of the East Asian summer monsoon (EASM) is closely associated with the Silk 
Road pattern (Hsu and Lin 2007; Kosaka et al. 2011). Li and $\mathrm{Lu}$ (2017) suggest that increased precipitation in the Yangtze River basin is linked to northeasterly anomalies to the north of the region. They argue that the northeasterly anomaly in the lower troposphere is associated with the cyclonic anomaly over East Asia in the upper troposphere, and that the latter is induced by the Silk Road pattern along the westerly jet. In fact, behavior of the Silk Road pattern is closely linked to the meridional position of Asian westerlies (Hong and Lu 2016; Hong et al. 2018). For instance, Hong and Lu (2016) suggest that when the jet is displaced southward, the Silk Road pattern tends to present as cyclonic anomalies over East Asia, and vice versa. Hong et al. (2018) further demonstrate that the Silk Road pattern is more pronounced when the jet is located to north of the Tibetan Plateau. Taken together, these studies suggest that westerlies might affect the mei-yu through modulating the variation of the Silk Road pattern.

On the other hand, precipitation over central eastern China during the mei-yu exhibits strong correlation with ascending motion and horizontal warm advection in the midtroposphere (e.g., Sampe and Xie 2010). This strong correlation led Sampe and Xie (2010) to conclude that the westerly jet anchors the mei-yu rainband via the advection of warm air from the southeastern flank of the Tibetan Plateau, which is then lifted upward over East Asia, thereby inducing convection. This argument attributes the demise of the mei-yu to the northward migration of the jet away from the maximum midtropospheric temperature center; this interpretation is further supported by studies on variations of East Asian summer rainfall at interannual time scales (Kosaka et al. 2011).

A different view of the role of the westerlies on the mei-yu was postulated by Molnar et al. (2010). They focus on the effect of the westerlies impinging on the Tibetan Plateau in altering the downstream circulation, specifically producing a locus of moisture convergence that defines the mei-yu rainband. In this view, the demise of the mei-yu rainband is dynamically tied to the northward seasonal migration of the westerlies from south to north of the plateau: when the core of the westerlies migrates off the plateau, the mechanical forcing of the plateau disappears, and so does the mei-yu rainband. From an energetic and moisture budget perspective, Chen and Bordoni (2014) argued that the extratropical northerlies downstream of the Tibetan Plateau are crucial in maintaining the mei-yu front via advecting dry enthalpy and strengthening the moisture convergence over central eastern China.

The above studies suggested different processes for how the westerlies affect the mei-yu. Although the origins of these mechanisms are independent, they consistently indicate the meridional position of the westerly jet relative to the Tibetan Plateau is key to formation and maintenance of the mei-yu. However, how this dynamically relates to the demise of the mei-yu has not been examined in detail; this is the focus of this paper. ${ }^{1}$ Furthermore, since the termination of the meiyu is abrupt, it raises the question of whether a latitude threshold in terms of jet position exists over the plateau that triggers the mei-yu termination. A recent modeling study on seasonal transitions of the jet and of the EASM during the Holocene suggests exactly this (Kong et al. 2017). In that study, the maximum in the 200-mb $(1 \mathrm{mb}=1 \mathrm{hPa})$ westerly jet over the Tibetan Plateau $\left(80^{\circ}-100^{\circ} \mathrm{E}\right)$ was found to be located at $40^{\circ} \mathrm{N}$ during the mei-yu onset, and the jet axis migrates northward by $1^{\circ}$ or $2^{\circ}$ when the mei-yu ends. Notably, $40^{\circ} \mathrm{N}$ is the latitude where the mean plateau elevation across $80^{\circ} \mathrm{E}-100^{\circ} \mathrm{E}$ drops below $1.5 \mathrm{~km}$, marking the northern edge of the plateau. It suggests that $40^{\circ} \mathrm{N}$ acts as this threshold, and mei-yu ends when the jet core migrates to north of $40^{\circ} \mathrm{N}$.

In this study, we confirm previous findings (Kong et al. 2017) that the termination of the mei-yu indeed coincides with the maximum upper tropospheric westerlies over the Tibetan Plateau shifting north of $40^{\circ} \mathrm{N}$. We also find that these changes are accompanied with disappearance of tropospheric northerlies over northeastern China $\left(35^{\circ}-40^{\circ} \mathrm{N}\right)$. We show that these concurrent behaviors hold from climatology to interannual and synoptic time scales, which motivate us to hypothesize that migration of the jet impinging over the plateau to north of $40^{\circ} \mathrm{N}$ causes the weakening of orographic downstream northerlies, and that this weakening in northerlies over central-northeastern China acts to terminate the mei-yu.

Mountains have long been held to be important in shaping the circulation and climate in the Northern Hemisphere midlatitudes (Bolin 1950; Broccoli and Manabe 1992; Manabe and Terpstra 1974). Model simulations have suggested that the presence of the orography over Asia is essential for the existence of the Asian monsoon (Hahn and Manabe 1975; Kitoh 2004; Park et al. 2012; Wong et al. 2018; Wu et al. 2012). A widely held view is that elevated sensible heating over the Tibetan Plateau drives the EASM (Flohn 1957; Li and Yanai 1996; Wu et al. 2012; Yeh et al. 1959). However, this view is challenged by studies that emphasized the role of the mechanical influence of the Tibetan

\footnotetext{
${ }^{1}$ As mentioned at the beginning of this section, the mei-yu is a more distinct rainfall stage of the EASM compared to midsummer. So we phrase the focus of this paper in terms of termination of the mei-yu, instead of onset of midsummer (or post-mei-yu).
} 
Plateau on its surrounding circulations (e.g., Molnar et al. 2010; Park et al. 2012; Staff Members 1958).

In this study, we argue that topographically forced stationary waves provide a potential dynamical link between the westerlies impinging on the Tibetan Plateau and the downstream northerly response. In the midlatitudes, the linear response of the atmosphere to orographic forcing shows equatorward propagation of the stationary Rossby wave and the generation of lowlevel cyclonic motion downstream of the mountain (Cook and Held 1992; Held 1983; Hoskins and Karoly 1981). Following these studies, we attribute variations of northerlies over northeastern China to changes in the strength of the cyclonic circulation downstream of the plateau. We argue that migration of the jet to the north of the plateau weakens the orographic forcing and thus weakens the cyclonic circulation, leading to weakening and even disappearance of the northerlies.

We describe the data, methodology, and experiments in the next section. In section 3, we show how the climatological mean atmospheric circulation changes during the mei-yu termination. We then examine the variation of the mei-yu termination at interannual time scales and mei-yu-like rainfall patterns at synoptic scales in section 4. We explore how weakening of northerlies over central-northern eastern China affects the mei-yu termination in section 5 . In section 6 , we propose a hypothesis on the mei-yu termination and employ idealized simulations to test the response of northerlies and mei-yu termination to changes in the orographic forcing by perturbing the northern edge of the Tibetan Plateau. We then use the dry dynamical core of a general circulation model (GCM) to explore the change to the orographic downstream northerlies as the location of westerlies changes from south to north of the plateau (section 7). We close the paper with summaries in section 8 .

\section{Data, methods, and experiments}

\section{a. Data}

We use winds, geopotential height, temperature, and specific humidity from the European Centre for MediumRange Weather Forecasts (ECMWF) interim reanalysis (ERA-Interim) products (Dee et al. 2011), spanning the 29-yr period from 1979 to 2007. Daily fields are obtained by averaging the 6-hourly products mapped onto a $1^{\circ} \times 1^{\circ}$ grid on the standard pressure levels.

As with Kong et al. (2017), we use the APHRO_MA 025deg_V1003R1 product from the APHRODITE rain gauge data (Yatagai et al. 2009) to present summer rainfall in East Asia. We focus on the period of 1979-2007 for consistency with the ERA-Interim dataset.

\section{b. Self-organizing maps}

Following Chiang et al. (2017) and Kong et al. (2017), we use self-organizing maps (SOMs) (Kohonen 2001; Kohonen et al. 1996) to objectively extract the seasonal EASM rainfall stages and identify the termination of the mei-yu. The SOM is a neural network-based cluster analysis that classifies a high-dimensional dataset into representative patterns (Kohonen 2001; Kohonen et al. 1996). This method has been applied successfully to extract patterns of El NiñoSouthern Oscillation (Johnson 2013) and the Northern and Southern Hemisphere teleconnections (Chang and Johnson 2015; Johnson et al. 2008). It has also been used on the intraseasonal oscillation of the Indian summer monsoon (Chattopadhyay et al. 2008) and the East Asian-western North Pacific summer monsoon (Chu et al. 2012).

The SOM analysis of the APHRODITE daily climatology used in this study is similar to that in Kong et al. (2017), to which the readers are referred for details. This study differs from Kong et al. (2017) in that we focus on a shorter period covering 1979-2007 and that we use the 9-day running mean [instead of the 5-day mean as in Kong et al. (2017)] of daily climatology for the SOM analysis.

\section{c. Definition of jet position}

We quantify the position of the westerly jet over the plateau based on its axis at $200 \mathrm{mb}$. We first zonally average the zonal wind at $200 \mathrm{mb}$ between $80^{\circ}$ and $100^{\circ} \mathrm{E}$, overlapping with the main body of the Tibetan Plateau. We then identify the location of the maximum zonal wind between $20^{\circ}$ and $50^{\circ} \mathrm{N}$ as the jet axis impinging on the plateau. We restrict the search latitudes to $20^{\circ}-50^{\circ} \mathrm{N}$ in order to exclude the potential identification of the polar front jet at higher latitudes.

\section{d. Model experiments}

We use the National Center for Atmospheric Research's (NCAR) Community Earth System Model (CESM) version 1.2.2 (Hurrell et al. 2013). Previous work (Chiang et al. 2015; Kong et al. 2017) shows that this model simulates the seasonality of the EASM with fidelity. We design two sets of experiments: 1) testing the behavior of the mei-yu under "northward-extended plateau" scenarios, and 2) testing responses of orographic downstream northerlies by perturbing relative positioning of westerlies to the plateau in idealized simulations with a dry dynamical core.

For the northward-extended plateau simulations (section 7), we use the F_1850_CAM5 component set (Vertenstein et al. 2011), which includes the coupler, active atmosphere, land, and ice components, and a data ocean model with fixed sea surface temperature (SST). The atmospheric component of the CESM1 is the Community Atmosphere 
Model version 5 (CAM5) (Neale et al. 2010) at $0.9^{\circ} \times 1.25^{\circ}$ horizontal resolution and with 30 vertical layers. We conduct four simulations, namely, Plateau_control, Plateau_3deg, Plateau_6deg, and Plateau_10deg. The only difference among these simulations is the meridional dimension of the Tibetan Plateau. Plateau_3deg, Plateau_ $6 \mathrm{deg}$, and Plateau_10deg represent scenarios where the northern edge of the plateau is extended northward by $3^{\circ}, 6^{\circ}$, and $10^{\circ}$, respectively. To generate topography files for these simulations, we first modify a global elevation dataset mapped onto the model grid $\left(0.9^{\circ} \times 1.25^{\circ}\right)$, which is obtained from NCAR's supercomputer. We then use the NCAR Global Model Topography Generation Software (Lauritzen et al. 2015) to smooth the modified topography files.

Figure A1 (see the appendix) shows the boundary topography in East Asia for these simulations. We take the Plateau_3deg run as an example to describe how we extended the northern edge of the Tibetan Plateau. We first target the region $35^{\circ}-55^{\circ} \mathrm{N}, 60^{\circ}-110^{\circ} \mathrm{E}$ (simply called the "source region" hereafter), as highlighted by the black box in Fig. A1a. We then shift the elevation in this region northward by $3^{\circ}$, replacing the elevation in the region $38^{\circ}-58^{\circ} \mathrm{N}, 60^{\circ}-110^{\circ} \mathrm{E}$ (the black box in Fig. A1b) with the elevation of the source region. By doing so, we leave a topographic gap in the middle of the plateau, as indicated by the dashed box in Fig. A1b. We fill the gap with the elevation of today's Tibetan Plateau around that latitude. Figures A1e-h present the vertical cross sections of modified elevation in the plateau region.

The greenhouse gas (GHG) concentrations are set to default values as in the CESM preindustrial configuration (i.e., $\mathrm{CO}_{2}$ is $284.7 \mathrm{ppm}, \mathrm{CH}_{4}$ is $791.6 \mathrm{ppb}$, and $\mathrm{N}_{2} \mathrm{O}$ is $275.68 \mathrm{ppb}$ ). The prescribed SST dataset is derived from the merged Hadley optimum interpolation (OI) SST and sea ice concentration (SIC) dataset (Hurrell et al. 2008). Each experiment is integrated for 25 years, with the first 5 years discarded to avoid model drift; the climatology derived over the last 20 years is used for the analysis presented here.

For the idealized simulations (section 8), we use the F_IDEAL_PHYS component, that is, the finite volume dynamical core of CAM5, which is based on the model described by Held and Suarez (1994). This idealized physics configuration is hemispheric and zonally symmetric, with neither a seasonal cycle nor land-sea contrast. It employs a Newtonian relaxation toward a prescribed zonal mean radiative equilibrium temperature profile to represent radiative cooling, with a relaxation time scale of 40 days. There is neither moisture nor diabatic heating in the dry dynamical core, which allows us to neglect the possible effects of the sensible heating and condensational heating on the atmospheric circulation. We introduce the Tibetan Plateau in the model by setting the surface geopotential over $25^{\circ}-45^{\circ} \mathrm{N}$, $60^{\circ}-105^{\circ} \mathrm{E}$ to today's value. To obtain a relatively localized plateau, elevations lower than $500 \mathrm{~m}$ in the region are set to zero. We shift the plateau meridionally to perturb relative positioning between westerlies and orography; by doing so, we mimic the seasonal migration of the westerly jet across the plateau. We undertake five simulations, namely Plateau, PlateauN3, PlateauN6, PlateauS3, and PlateauS6. The "Plateau" simulation is the case where the Tibetan Plateau is fixed at its present location, while the other cases represent scenarios where the plateau is shifted northward or southward by $3^{\circ}$ or $6^{\circ}$. Each simulation is integrated for 5 years, with 30 levels in the vertical, at a horizontal resolution of $0.9^{\circ} \times 1.25^{\circ}$ (as with the northward-extended plateau simulations). An initial spinup period of 2 years is discarded, leaving 3 years of data for analysis.

For the boundary orography in the CAM5, the resolved grid scale component is the mean elevation in each grid box (i.e., the surface geopotential). The unresolved subgrid-scale orography is parameterized as the turbulent mountain stress (TMS) and the gravity wave drag (GWD) (Neale et al. 2010). In our simulations with both modified resolved and modified subgrid topography, the subgrid-scale variances needed for TMS and GWD parameterizations were derived from the modified resolved topography (e.g., Fig. A1) using the NCAR Global Model Topography Generation Software (Lauritzen et al. 2015). Thus, the subgrid-scale variances are modified to be consistent with the modified resolved topography.

\section{Termination of mei-yu in climatology}

In this section, we show that the mei-yu termination in observed climatology is accompanied by the migration of core westerlies impinging on the Tibetan Plateau to the north of $40^{\circ} \mathrm{N}$ and the disappearance of northerlies in northeastern China $\left(35^{\circ}-45^{\circ} \mathrm{N}, 110^{\circ}-120^{\circ} \mathrm{E}\right)$.

\section{a. Identification of the mei-yu termination in climatology}

Figure $1 \mathrm{~g}$ presents the temporal evolution of the climatological precipitation over eastern China $\left(110^{\circ}-\right.$ $120^{\circ} \mathrm{E}$ ), with dashed lines indicating timings of the rainfall stages derived from the SOMs analysis of the APHRODITE data (Fig. 1a). Figure 1a shows the temporal extent of each of the five rainfall patterns illustrated in the remaining panels, namely spring (pattern 1; Fig. 1b), pre-mei-yu (pattern 2; Fig. 1c), mei-yu (pattern 3; Fig. 1d), midsummer (pattern 4; Fig. 1e), and fall (pattern 5; Fig. 1f). Observational studies (Ding and Chan 2005; Tao and Chen 1987) suggest that the typical 

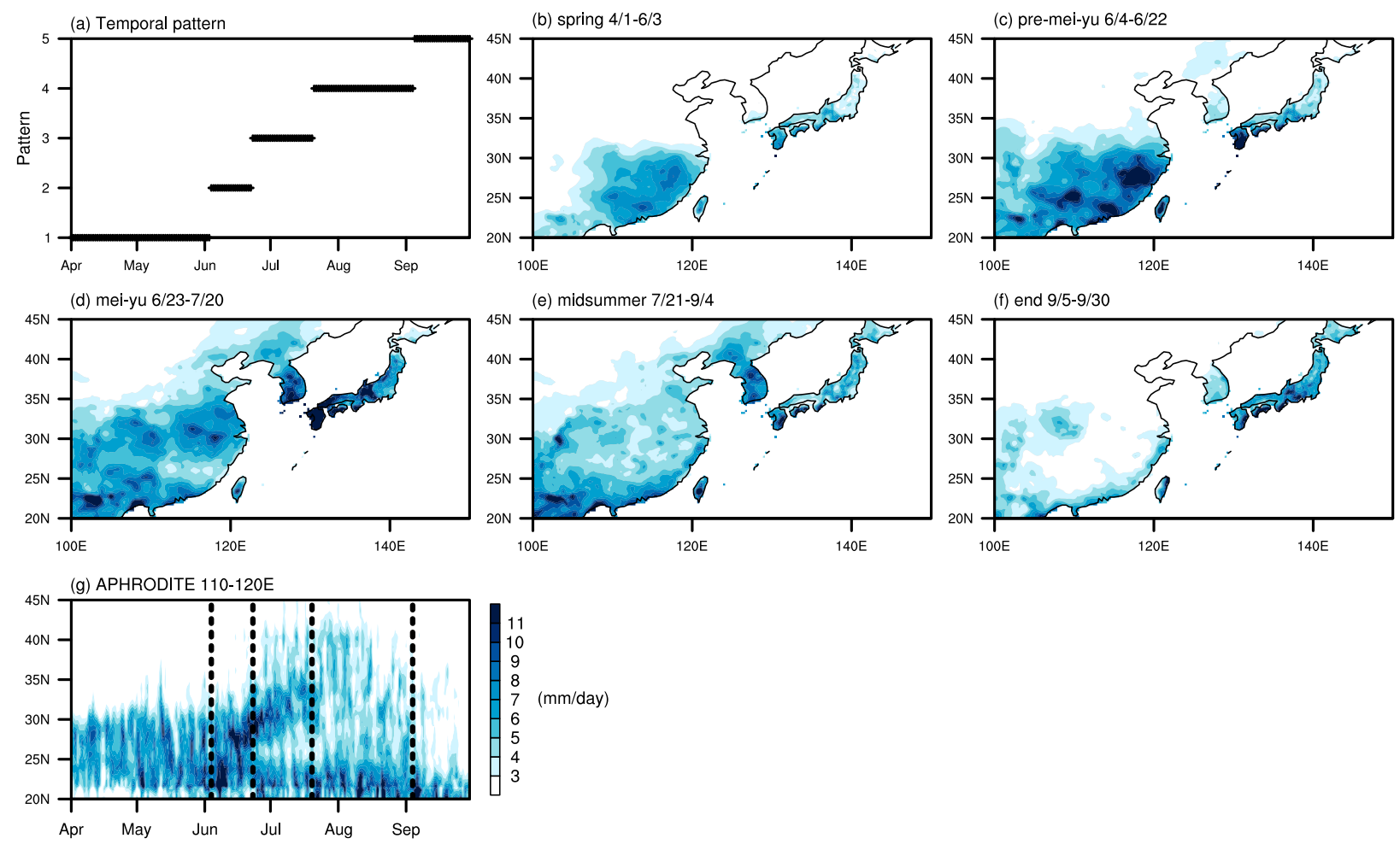

FIG. 1. Climatology of the 1979-2007 APHRODITE daily precipitation rate (mm day ${ }^{-1}$ ) in East Asia. (a) Temporal and (b)-(f) spatial patterns of EASM derived from the SOM analysis of the APHRODITE dataset. Patterns 1-5 [shown in (b)-(f)] are respectively the spring persistent rainfall (1 Apr-3 Jun), pre-mei-yu (4-22 Jun), mei-yu (23 Jun-20 Jul), midsummer (21 Jul-4 Sep), and retreat of the EASM (5-30 Sep). (g) Hovmöller diagram of precipitation rate averaged from $110^{\circ}$ to $120^{\circ} \mathrm{E}$. Dashed lines in ( $\mathrm{g}$ ) denote timings of seasonal transitions based on the SOMs analysis.

mei-yu season lasts from mid-June to mid-July. The SOM-captured timing of the mei-yu spans the interval from 23 June to 20 July, approximately matching this reported timing. For spatial patterns, the SOM-derived mei-yu covers the Yangtze River valley $\left(27^{\circ}-34^{\circ} \mathrm{N}, 100^{\circ}-\right.$ $120^{\circ} \mathrm{E}$ ), which is consistent with the previously defined domain (Ding and Chan 2005).

The mei-yu front is characterized by a strong meridional moisture gradient (Chen and Chang 1980; Ding 1992) and can be identified from sharp meridional gradients in equivalent potential temperature $\theta_{e}$ (Ninomiya 1984, 2000; Ninomiya and Shibagaki 2007). Figure 2 shows the meridional gradient of $\theta_{e}\left[-\left(\partial \theta_{e} / \partial y\right)\right]$. Here, $\theta_{e}$ is approximately defined as $\theta_{e}=\theta+L_{v} q / c_{p}$ (Shaw and Pauluis 2012), and the largest values of $-\left(\partial \theta_{e} / \partial y\right)$ indicate the location of the front. We interpret the latitudinal migration of the band of strong gradient to indicate the meridional movement of the frontal system. Figure 2a presents the seasonal evolution of $-\left(\partial \theta_{e} / \partial y\right)$ over East China $\left(110^{\circ}-120^{\circ} \mathrm{E}\right)$ at $850 \mathrm{mb}$. It shows that the maximum gradient, and hence the front, migrates northward during the mei-yu and disappears by midsummer. Vertical cross sections further show weakening of the front in central eastern China $\left(30^{\circ}-35^{\circ} \mathrm{N}, 110^{\circ}-120^{\circ} \mathrm{E}\right)$ from mei-yu to midsummer (Figs. 2b,c). Figures $2 \mathrm{~d}$ and $2 \mathrm{e}$ depict the meridional moisture gradient and suggest that the moisture contrast over central eastern China weakens from mei-yu to midsummer.

Strong midtropospheric $(500 \mathrm{mb})$ ascending motion over central eastern China is also thought to be representative for the mei-yu season (Sampe and Xie 2010). Figure 3a shows the ascending motion at $500 \mathrm{mb}$ and suggests that our SOM analysis accurately captured the mei-yu and midsummer stages. Both spatial distribution (Figs. 3b,c) and vertical cross sections (Figs. 3d,e) further indicate significant weakening of the ascending motion over central eastern China from mei-yu to midsummer.

\section{b. Threshold latitude of jet for the mei-yu termination}

Figure 4a shows the seasonal migration of $200-\mathrm{mb}$ westerlies averaged over $80^{\circ}-100^{\circ} \mathrm{E}$, where the plus sign (+) symbol indicates the latitude of maximum westerlies. Resembling model results from Kong et al. (2017) but now from observational data, the mean jet axis over the plateau is located at $40^{\circ} \mathrm{N}$ for most of the mei-yu 

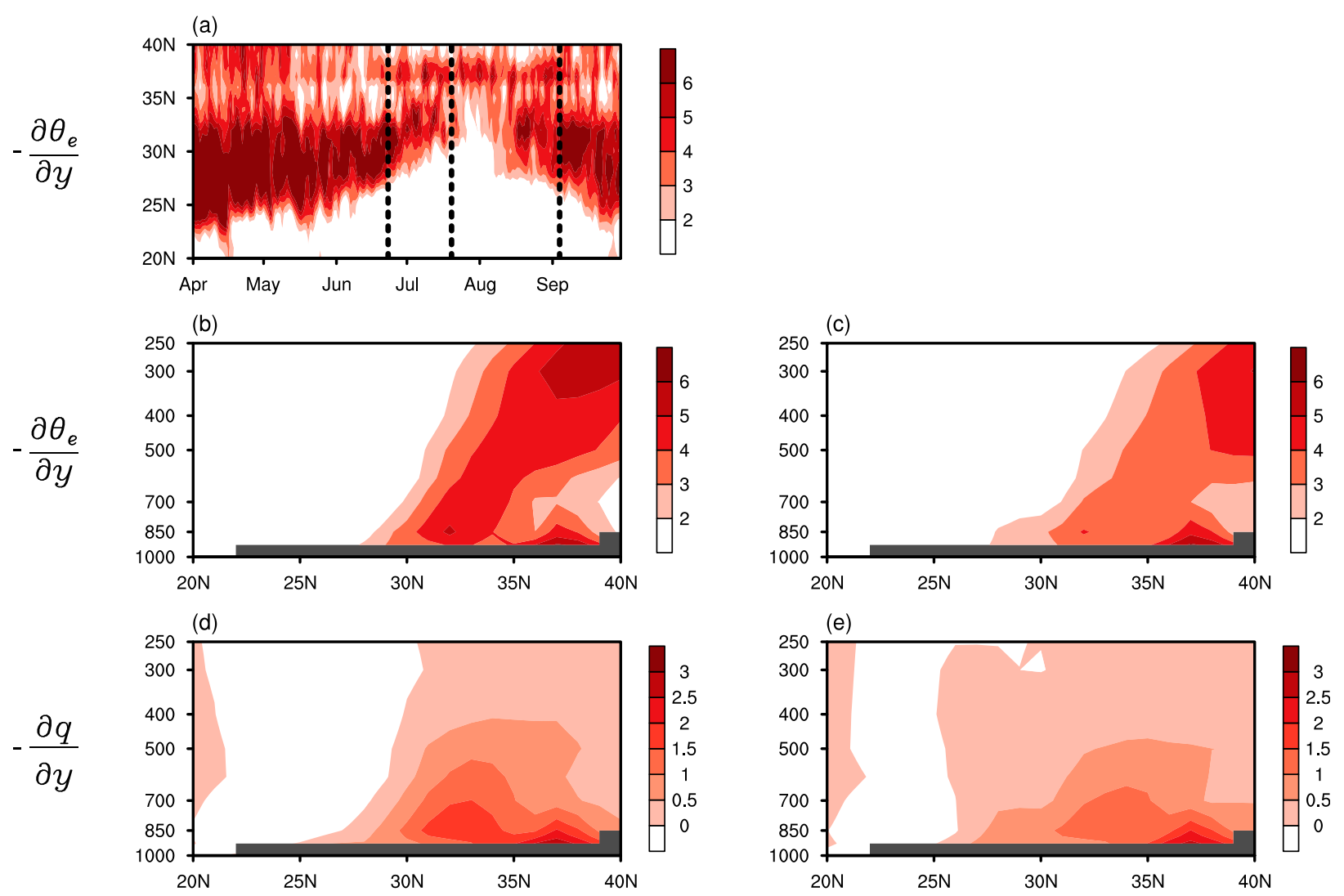

FIG. 2. Climatological meridional gradient of equivalent potential temperature $\left[-\left(\partial \theta_{e} / \partial y\right)\right]\left(3 \times 10^{-6} \mathrm{~K} \mathrm{~m}^{-1}\right)$ and meridional gradient of specific humidity $[-(\partial q / \partial y)]\left(3 \times 10^{-9} \mathrm{~kg} \mathrm{~kg}^{-1} \mathrm{~m}^{-1}\right)$ over 1979-2007. (a) Hovmöller diagram of $-\left(\partial \theta_{e} / \partial y\right)$ at $850 \mathrm{mb}$ in East China $\left(110^{\circ}-\right.$ $\left.120^{\circ} \mathrm{E}\right)$. Black dashed lines indicate SOM-derived timings for mei-yu and midsummer. Also shown are vertical cross sections of $-\left(\partial \theta_{e} / \partial y\right)$ over $110^{\circ}-120^{\circ} \mathrm{E}$ in (b) mei-yu and (c) midsummer and vertical cross sections of $-(\partial q / \partial y)$ over $110^{\circ}-120^{\circ} \mathrm{E}$ in (d) mei-yu and (e) midsummer.

season (Fig. 4a); it then migrates a few degrees northward during the transition from mei-yu to midsummer and stays at $42^{\circ}$ or $43^{\circ} \mathrm{N}$ for most of midsummer before retreating southward in late August. Figures $4 \mathrm{~b}-\mathrm{e}$ further depict the distinct shift of jet axis over the plateau from $40^{\circ} \mathrm{N}$ in mei-yu to around $42^{\circ} \mathrm{N}$ in midsummer. It suggests that $40^{\circ} \mathrm{N}$ marks a latitudinal threshold for the termination of mei-yu.

\section{c. Changes in orographic downstream northerlies from mei-yu to midsummer}

Previous studies suggested that the meridional wind plays an important role in the formation of the mei-yu (Chen and Bordoni 2014; Park et al. 2012). Figures 4f-j show variations of midtropospheric meridional wind from mei-yu to midsummer. During the spring and premei-yu stages, the extratropical northerlies are strong and converge with the tropical southerlies along $30^{\circ} \mathrm{N}$ over eastern China. The northerlies weaken and retreat to the north of $35^{\circ} \mathrm{N}$ during the mei-yu stage, while the southerlies become stronger and penetrate northward. During midsummer, the extratropical northerlies almost disappear, while the tropical southerlies penetrate to around $40^{\circ} \mathrm{N}$. Similar variation can be seen in the meridional winds at $700 \mathrm{mb}$ (not shown).

\section{Termination of the mei-yu on interannual and synoptic time scales}

In this section, we seek a more rigorous examination of the link between jet latitude, weakening of northerlies over northeastern China, and termination of the mei-yu on interannual and synoptic time scales.

\section{a. Termination of the mei-yu on interannual time scales}

The leading mode of summertime rainfall over East Asia exhibits a tripole pattern with rainfall over northern and southern China varying out of phase with rainfall over central China (Hsu and Lin 2007). Chiang et al. (2017) identified the leading mode of interannual variability of East Asian summer rainfall over 1951-2007 by deriving an empirical orthogonal function (EOF) from July-August APHRODITE rain gauge data (Fig. A2). 
(a)

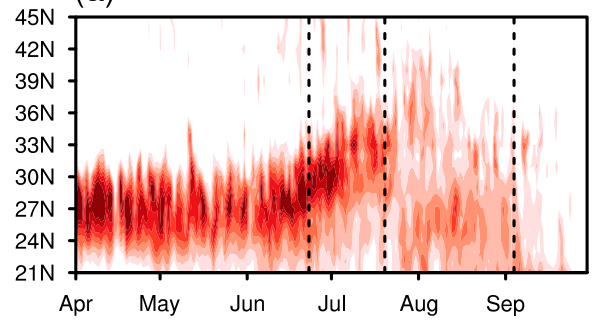

(b)

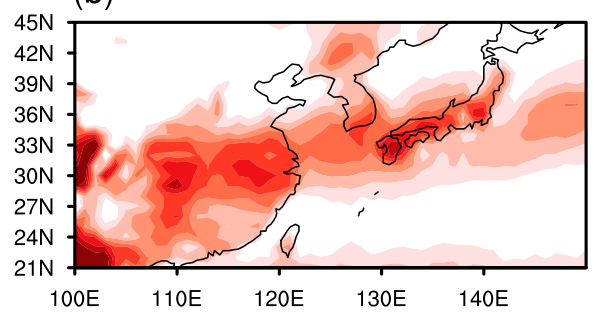

(d)

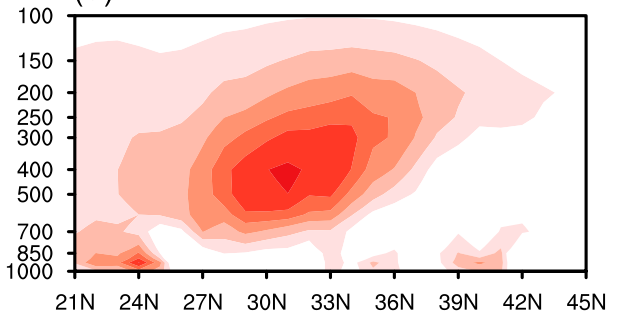

(c)

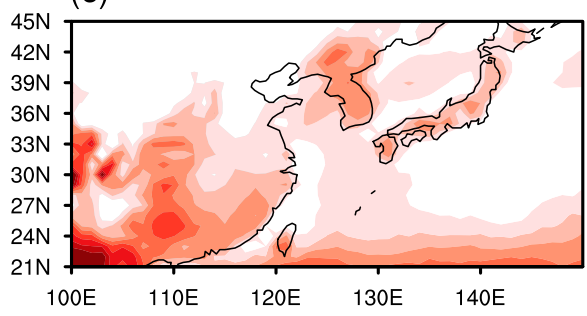

(e)

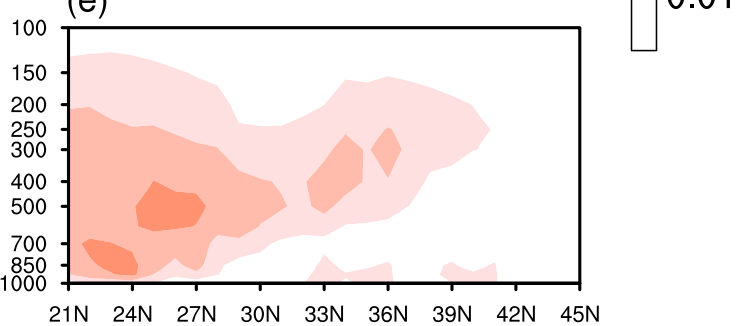

FIG. 3. Climatological vertical velocity $\omega\left(-\mathrm{Pa} \mathrm{s}^{-1}\right)$ over 1979-2007. (a) Hovmöller diagram of $\omega$ at $500 \mathrm{mb}$ in East China $\left(110^{\circ}-120^{\circ} \mathrm{E}\right)$. Black dashed lines indicate SOM-derived timings for mei-yu and midsummer. Also shown are spatial patterns of $\omega$ at $500 \mathrm{mb}$ in (b) mei-yu and (c) midsummer, and vertical cross sections of $\omega$ over $110^{\circ}-120^{\circ} \mathrm{E}$ in (d) mei-yu and (e) midsummer. Warm color indicates ascent.

They attributed one phase of the tripole pattern-with wet northern and southern China and dry central Chinato a significantly earlier termination of the mei-yu, accompanied by a shorter mei-yu duration and longer midsummer stage. They found that the years with earlier mei-yu termination are associated with earlier northward migration of westerlies over the Tibetan Plateau.

Here, we examine the linkage between the jet positioning, strength of northerlies, and the mei-yu in the context of the interannual variation of mei-yu termination. We select anomalous high and low years based on the first principal component of Chiang et al. (2017) (Fig. A2b), but limited to 1979-2007, which is the time span of the ERA-Interim data we use. We identify 7 high years and 9 low years based on the principal component exceeding \pm 0.5 standard deviations. For each group of years, we compute the daily climatological rainfall between April and September, and applied a 9-day running average. To find the corresponding rainfall stages, we assign the averaged rainfall for each day to a bestmatching climatological SOM rainfall pattern (Figs. 1b-f) based on the minimum Euclidean distance between each daily pattern and each of the SOM patterns. Similar to Chiang et al. (2017), the matched timing for high and low years suggests that the mei-yu in low years terminates three weeks later than in high years (Figs. 5a,b).

Hovmöller diagrams of the meridional gradient of $\theta_{e}$ (Figs. 5c,d) and midtropospheric ascending motion (Figs. 5e,f) suggest that the mei-yu stages identified by the SOM analysis are reliable for both categories. Meiyu stages of both high and low years are accompanied by sharp gradients of $\theta_{e}$ over central eastern China; termination of the mei-yu is accompanied by weakening of the gradient of $\theta_{e}$ and northward migration of the maximum gradient to north of $35^{\circ} \mathrm{N}$, which is however more evident in the lower years than the high years. Similarly, both high and low years exhibit significant weakening of midtropospheric ascending motion over central eastern China when the mei-yu ends (Figs. 5e,f).

The associated behaviors of the jet latitude over the plateau and northerlies over eastern China for both composites are consistent with the climatology. The main feature to note is that the jet axis remains at $40^{\circ} \mathrm{N}$ during the mei-yu stage for both high and low years; this 
(a) $200 \mathrm{mb}(80 \mathrm{E}-100 \mathrm{E})$

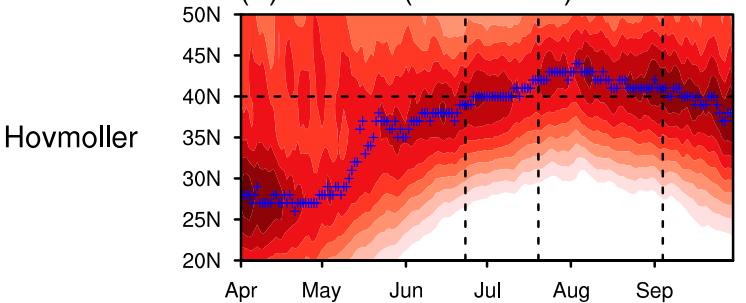

(b) $200 \mathrm{mb}$

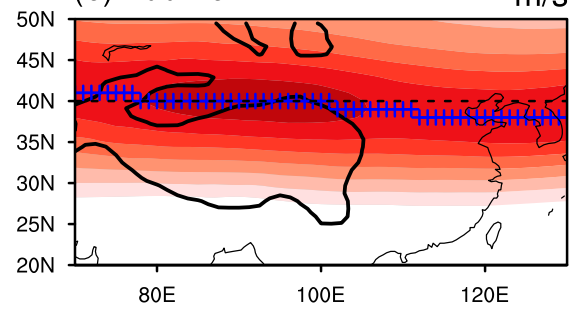

(c) $200 \mathrm{mb}$

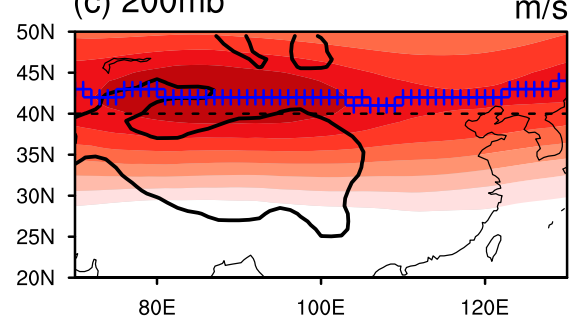

(d) $80 \mathrm{E}-100 \mathrm{E}$

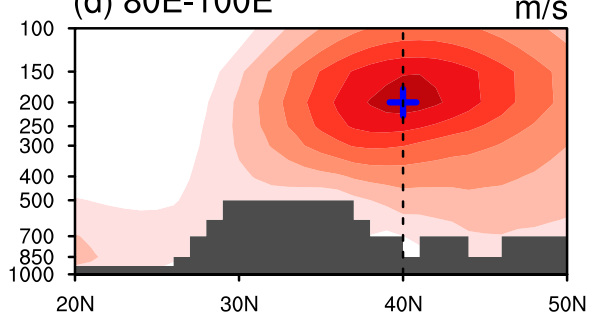

(e) $80 \mathrm{E}-100 \mathrm{E}$

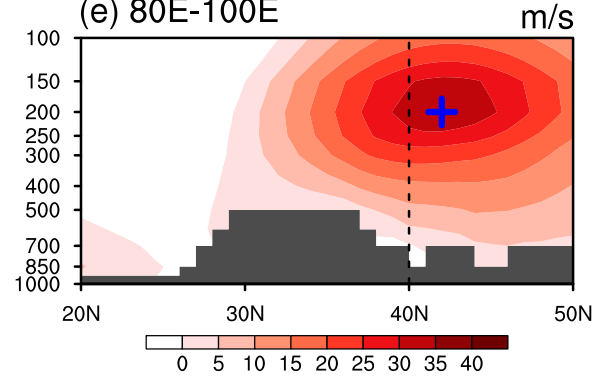

(f) $500 \mathrm{mb}(110 \mathrm{E}-120 \mathrm{E})$

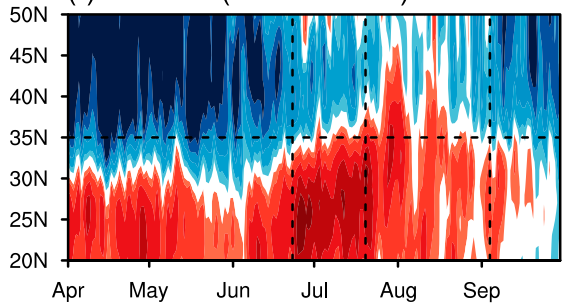

(g) $500 \mathrm{mb}$

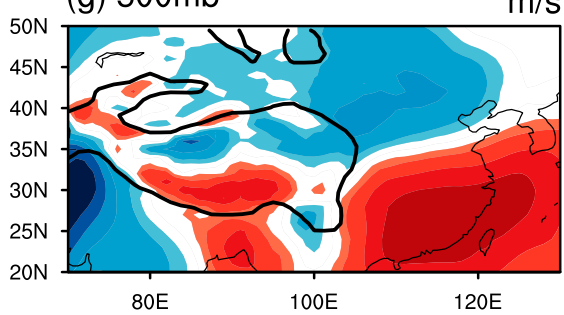

(h) $500 \mathrm{mb}$

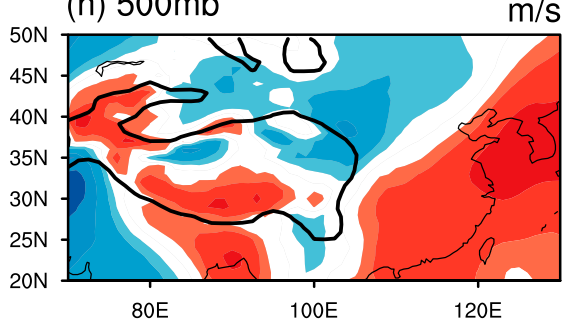

(i) $110 \mathrm{E}-120 \mathrm{E}$

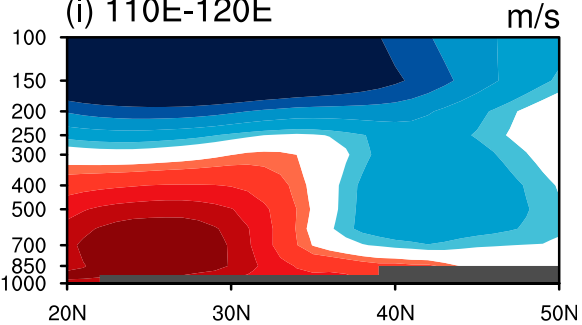

(j) $110 \mathrm{E}-120 \mathrm{E}$

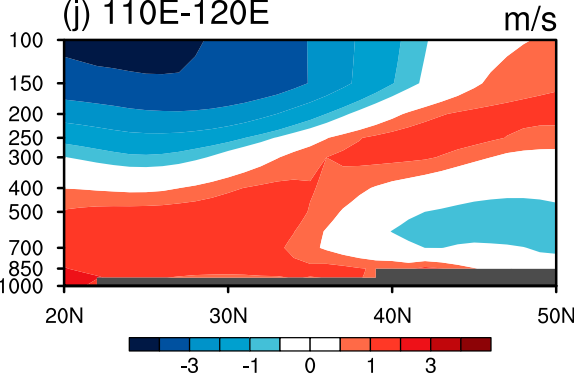

FIG. 4. (left) Zonal wind and (right) meridional wind characteristics over East Asia associated with the mei-yu and midsummer stages $\left(\mathrm{m} \mathrm{s}^{-1}\right)$. Hovmöller diagram of (a) zonal wind at $200 \mathrm{mb}$ averaged over $80^{\circ}-100^{\circ} \mathrm{E}$ and (f) meridional wind at $500 \mathrm{mb}$ averaged over $110^{\circ}-120^{\circ} \mathrm{E}$; vertical dashed lines in (a) and (f) indicate SOM-derived timings for mei-yu and midsummer, and blue crosses in (a) indicate the latitude position of maximum westerlies for each day. Also shown are maps of (b), (c) zonal wind at $200 \mathrm{mb}$ and $(\mathrm{g}),(\mathrm{h})$ meridional wind at $500 \mathrm{mb}$, for mei-yu in (b) and (g) and midsummer in (c) and (h), and pressure-latitude $\left(20^{\circ}-50^{\circ} \mathrm{N}\right)$ cross sections of (d), (e) zonal wind averaged over $80^{\circ}-100^{\circ} \mathrm{E}$ and (i),(j) meridional wind averaged over $110^{\circ}-120^{\circ} \mathrm{E}$, for mei-yu in (d) and (i) and midsummer in (e) and (j). Gray shadings indicate zonally averaged topography in (d) and (e) over $80^{\circ}-100^{\circ} \mathrm{E}$ and (i) and (j) over $110^{\circ}-120^{\circ}$ E. Black contours in (b), (c), (g), and (h) indicate an elevation of $2000 \mathrm{~m}$. 
High years

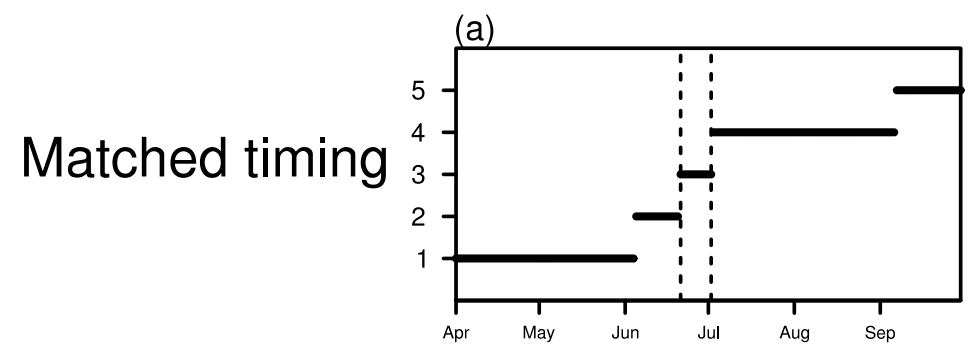

(c)

$-\frac{\partial \theta_{e}}{\partial y}$

$-\omega$

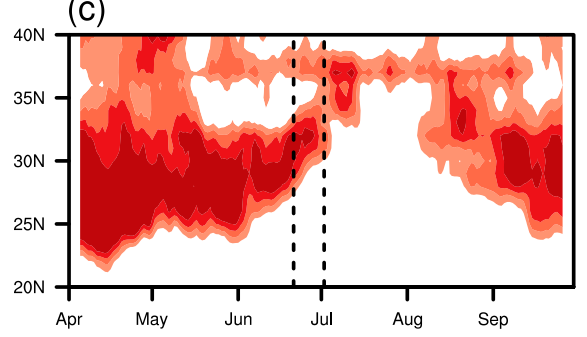

(e)

Low years

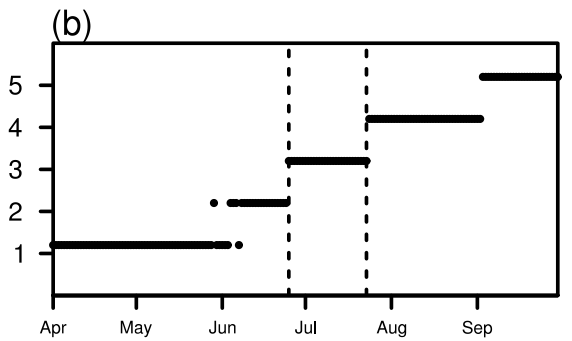

(d)
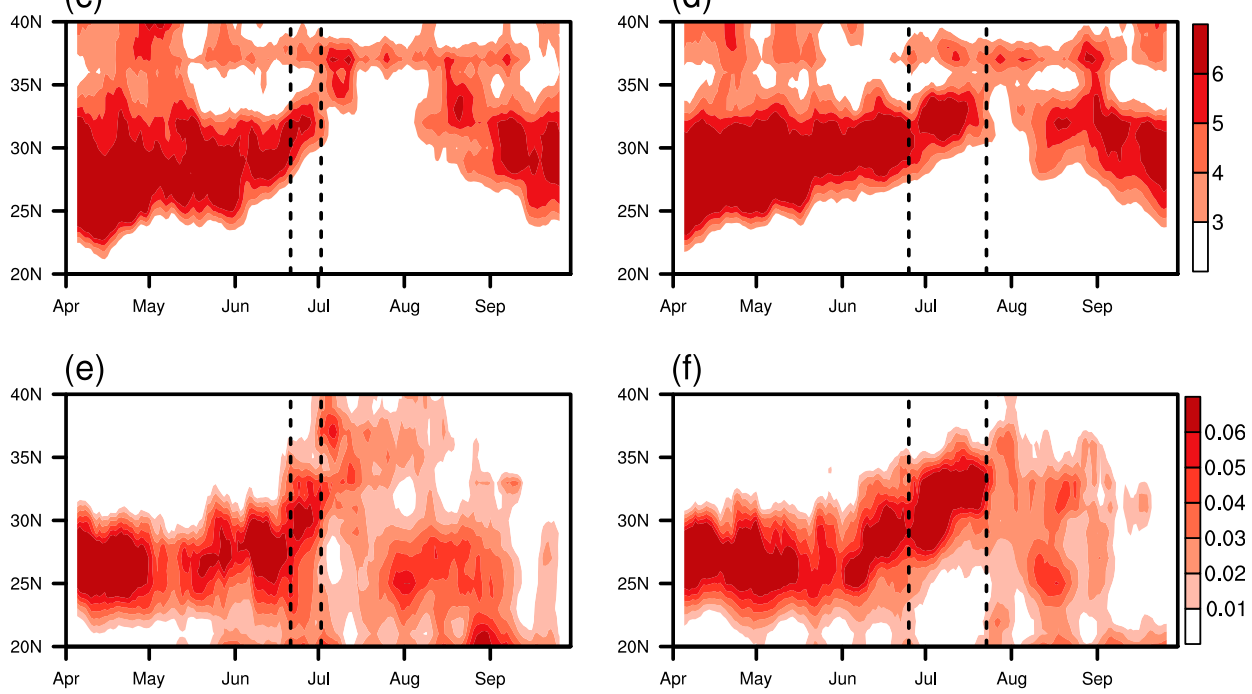

(g)

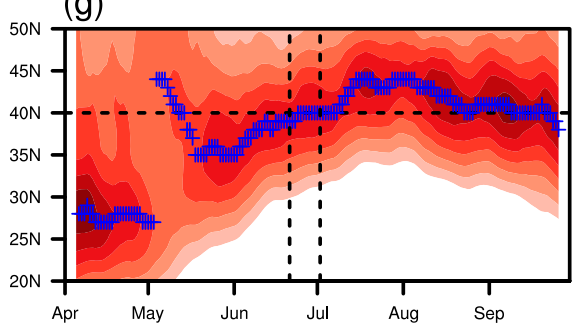

(h)

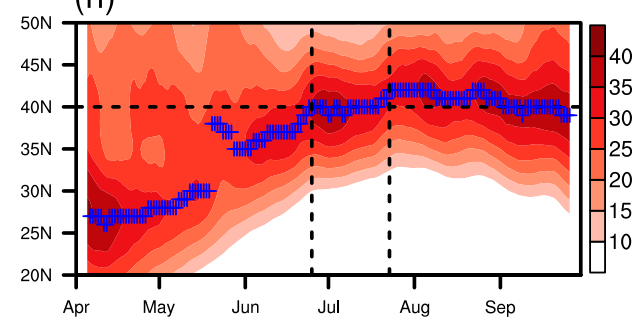

(i)

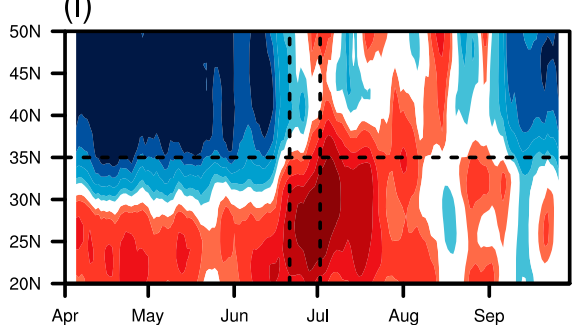

(j)

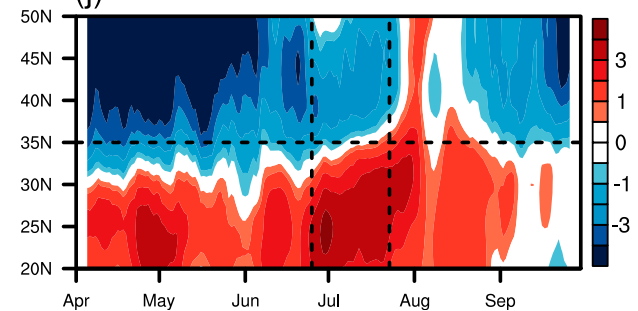

FIG. 5. Matched timings for 9-day running averaged daily climatology, for (a) high years and (b) low years. The $y$ axes in (a) and (b) label spring as 1, pre-mei-yu as 2, mei-yu as 3, midsummer as 4, and the end of the EASM season as 5. Also shown are Hovmöller diagrams for (left) high years and (right) low years: (c),(d) meridional gradient of 850 -mb equivalent potential temperature $\left[-\left(\partial \theta_{e} / \partial y\right)\right]$ averaged over $110^{\circ}-120^{\circ} \mathrm{E}\left(3 \times 10^{-6} \mathrm{~K} \mathrm{~m}^{-1}\right)$; (e),(f) ascending motion averaged over $110^{\circ}-120^{\circ} \mathrm{E}$ at $500 \mathrm{mb}\left(-\mathrm{Pa} \mathrm{s}^{-1}\right)$; (g),(h) zonal wind at $200 \mathrm{mb}$ averaged over $80^{\circ}-100^{\circ} \mathrm{E}\left(\mathrm{m} \mathrm{s}^{-1}\right)$; and(i), (j) meridional wind at $500 \mathrm{mb}$ averaged over $110^{\circ}-120^{\circ} \mathrm{E}\left(\mathrm{m} \mathrm{s}^{-1}\right)$. Black dashed lines in the left panel indicate the matched mei-yu period for high years, and black dashed lines in the right panel indicate the matched mei-yu period for low years. To remove weather noise, we applied a 9-day running mean to fields shown in (c)-(j). 
is despite the fact that the mei-yu stage has significantly longer duration in low years compared to the high years. Prior to the mei-yu, the jet axis is south of $40^{\circ} \mathrm{N}$ in both cases; after the mei-yu, the jet axis shifts north of $40^{\circ} \mathrm{N}$ (Figs. 5g,h). On the other hand, a weakening and retreat of the northerlies, and increased northward penetration of southerlies, appears at the transition from mei-yu to midsummer for both high and low years (Figs. 5i,j). It is worth noting that the southward retreat of westerlies toward the end of the summer monsoonal season is accompanied by a recurrence of northerlies in northeastern China, suggesting a causal link between the jet axis position relative to $40^{\circ} \mathrm{N}$ and the sign and strength of northerlies downstream of the plateau.

\section{b. Termination of the mei-yu on synoptic time scales}

Although the climatological westerlies exhibit a continuous northward migration from spring to summer (Figs. 4a and 5g,h), on synoptic time scales the jet exhibits large and rapid latitudinal excursions (Schiemann et al. 2009). This observation raises the question of whether the connection between the jet position, strength of northerlies, and occurrence of mei-yu-like regimes holds on synoptic time scales.

To test this, we assign each pentad from 1 April (pentad 19) to 27 September (pentad 54) for each year over 19792007 (a total of 1044 pentads) to the best-matched climatological SOM rainfall pattern based on the minimum Euclidean distance. This allows us to identify mei-yu-like pentads and to examine the associated circulations. In contrast to the smooth climatological timing of each pattern (red lines in Fig. 6a), the SOM-matched patterns on the pentad basis from each year exhibit large variations (blue lines in Fig. 6a). Figure $6 \mathrm{~b}$ shows the seasonal distribution of the assigned SOM patterns of the 1044 pentads. Specifically for the mei-yu pattern, Fig. $6 \mathrm{~b}$ suggests that mei-yu-like rainfall regimes could occur in spring or late summer, but are relatively rare at these times. Mid-June to mid-July is the period when the meiyu-like rain pattern most likely occurs.

We now discuss distributions of the jet axis impinging on the plateau (Fig. 6c) and strength of meridional winds over northeastern China (Fig. 6d). On the pentad scale, mei-yu-like patterns are most closely associated with jet axes ranging from $38^{\circ}$ to $41^{\circ} \mathrm{N}$, whereas midsummer-like pentads are associated with jet axes between $40^{\circ}$ and $43^{\circ} \mathrm{N}$. For the strength of the $500-\mathrm{mb}$ meridional wind over northeastern China, Fig. 6d suggests that northerly winds (negative values) are strongest when the rainfall is spring-like or pre-mei-yu-like; the northerlies tend to be weaker for mei-yu-like patterns. For midsummer-like patterns, the 500-mb meridional winds are both northerly and southerly, with a preference for the latter.
These findings suggest that the synoptic relationships between the jet positions, the strength of northerlies, and the rainfall stage are in general agreement with the ones inferred from the climatology.

We now examine the question from the opposite perspective. If we classify all 1044 pentads based instead on their positioning of the jet axis over the plateau, can we see weaker orographic downstream northerlies and midsummer-like rain patterns during pentads when the jet axis locates to the north of $40^{\circ} \mathrm{N}$, and vice versa? Figure 6e-which shows the jet latitude between April and September for each year from 1979 to 2007-indicates that jet latitude exhibits large synoptic variability about the climatological migration latitude (shown in red). There are overlaps in the jet latitudes between the mei-yulike pentads and the midsummer-like pentads when the jet latitude is associated with the corresponding rainfall stage (Fig. 6f; note that Fig. 6f is identical to Fig. 6c, although they are generated based on different approaches), suggesting that the correlation between the position of the jet and the mei-yu/midsummer regimes is not as tight as that on climatological (Fig. 4) and interannual time scales (Fig. 5). Regardless, the close synoptic relationship between the two is evident, namely that when the jet axis is between $38^{\circ}$ and $41^{\circ} \mathrm{N}$, the corresponding rainfall patterns are mei-yu-like, whereas jet axes occupying the interval bounded by $40^{\circ}$ and $43^{\circ} \mathrm{N}$ are midsummer-like. Likewise, when the jet latitude is associated with the corresponding value of the $500-\mathrm{mb}$ meridional wind, northeastern China more likely experiences northerlies when jet axes are south of $40^{\circ} \mathrm{N}$, whereas southerlies more likely appear in the region when the jet is north of $40^{\circ} \mathrm{N}$ (Fig. $6 \mathrm{~g}$ ).

Composites of pentads when the jet axis is located at $37^{\circ}, 40^{\circ}$, and $43^{\circ} \mathrm{N}$ are shown in Fig. 7. These composites confirm that the northerlies over northeastern China significantly weaken as the jet migrates from positions over the plateau to north of the plateau (Figs. $7 \mathrm{a}-\mathrm{f}$ ). The weakening of the meridional gradient of $\theta_{e}$ (Figs. 7g-i) and ascending motion (not shown) are all paced with the weakening of the northerlies. Finally, the pattern of rainfall extends northward with a more northward mean jet axis (Figs. $7 \mathrm{j}-1)$.

\section{Connections between northerlies and mei-yu termination}

In this section, we explore the dynamical connection between the disappearance of lower-to-midtropospheric northerlies and the mei-yu termination.

\section{a. General discussion}

One view of how the northerlies maintain the mei-yu is that they advect cold, dry air southward, meeting with 
(a) Assigned SOM pattern of APHRODITE (1979-2007 AMJJAS)
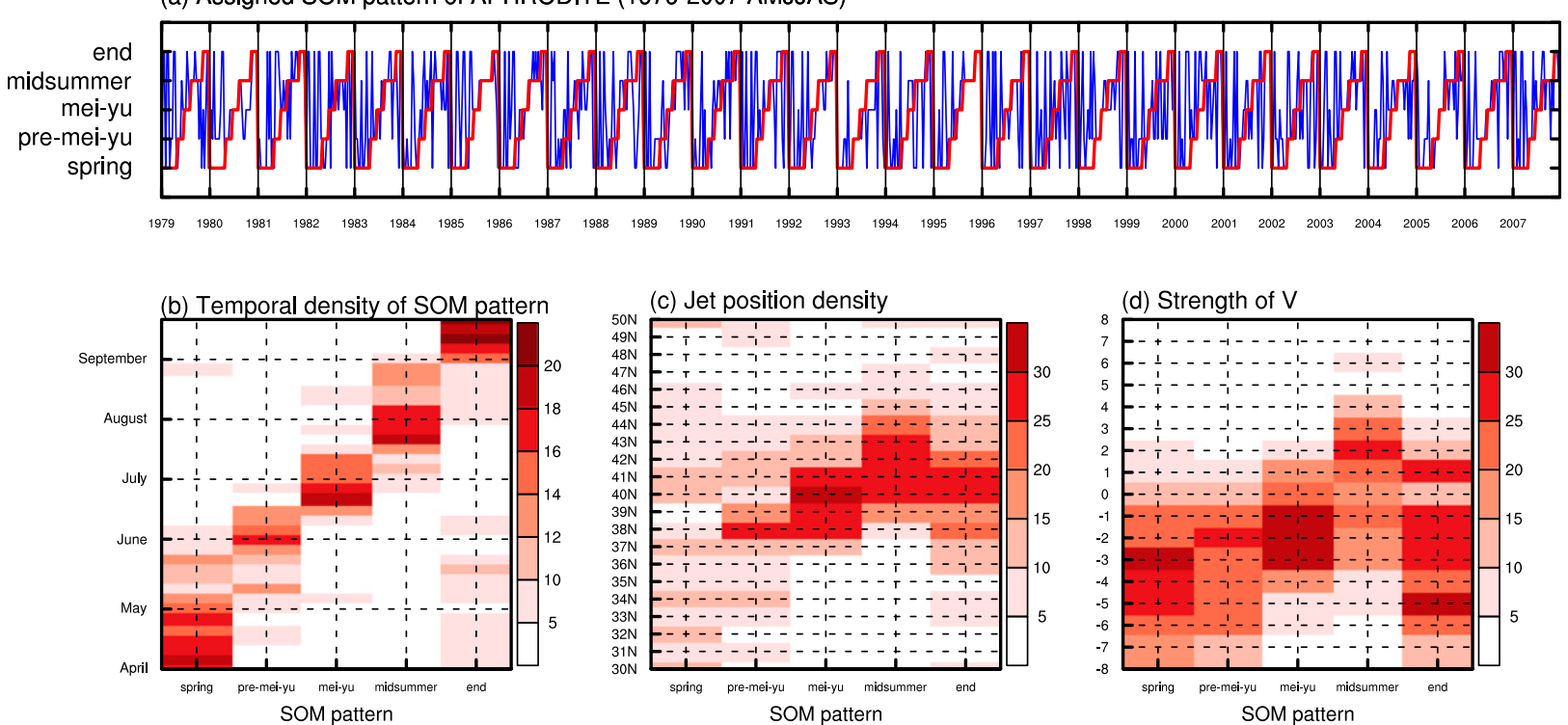

(e) Jet position (1979-2007 AMJJAS)
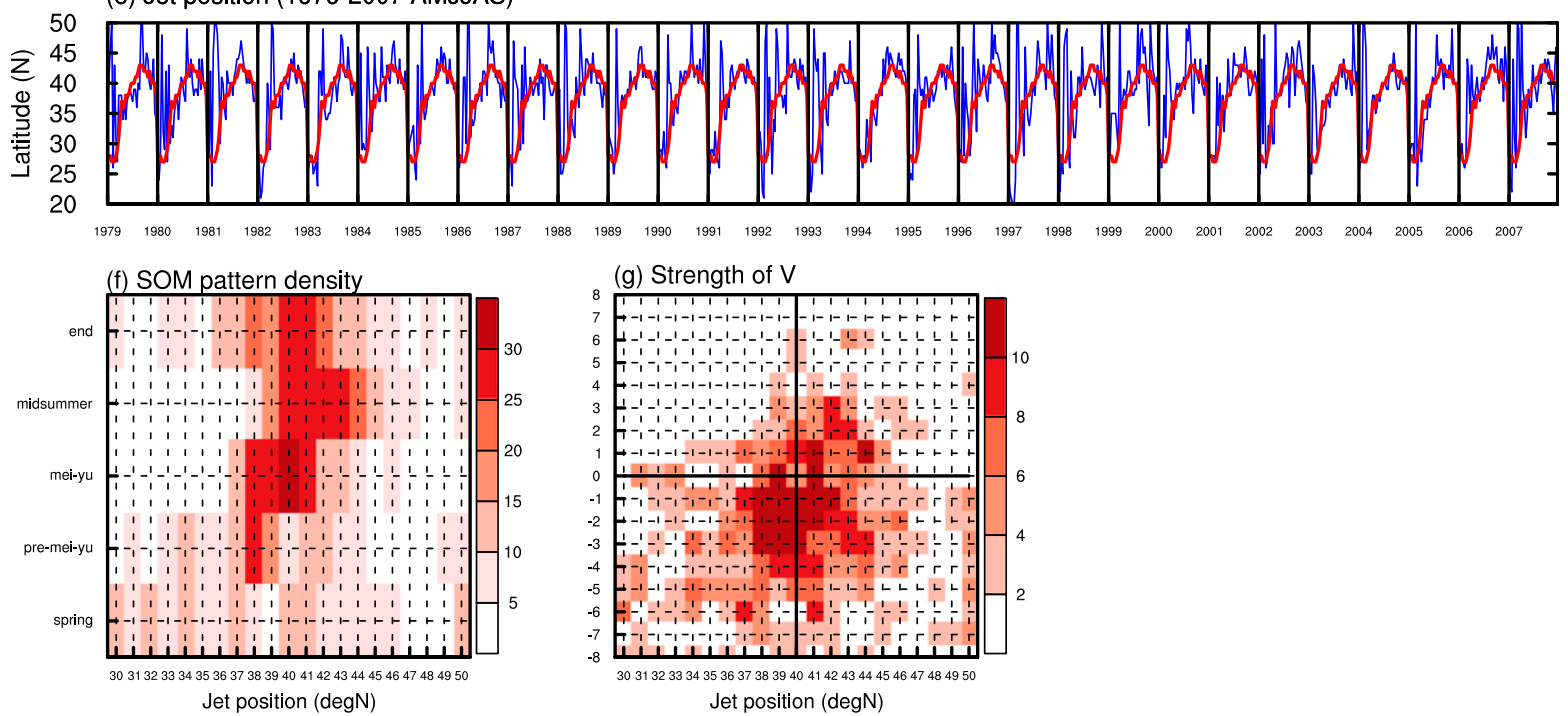

FIG. 6. (a) Timings of matched SOM patterns for each pentad from 1 Apr through 27 Sep in 1979-2007 (blue lines), overlaid with climatological SOM patterns (red lines). (b) Temporal density of matched SOMs patterns shown in (a); for each pentad at the $y$ axis, color for a corresponding SOMs pattern indicates the number of pentads in 1979-2007 April-September that are matched to that pattern. (c) Density of jet positions, where jet position is defined as latitude of maximum westerlies at $200 \mathrm{mb}$ in the Tibet region; for each SOM pattern, colors indicate the number of pentads when the jet is located at a certain latitude. (d) Density of the strength of meridional wind at 500 mb averaged over $110^{\circ}-$ $120^{\circ} \mathrm{E}, 35^{\circ}-40^{\circ} \mathrm{N}$; for each SOM pattern, colors indicate the number of pentads when the strength of meridional wind is within a certain range as indicated on the $y$ axis. (e) Jet position for each pentad in April through September from 1979 to 2007 (blue lines), overlaid with climatological jet position in 1979-2007. (f) SOM pattern density; for each jet position, colors indicate the number of corresponding pentads that are matched to a certain SOM pattern. (g) Density of strength of $V$; for each jet position, colors indicate the number of pentads when the strength of $V$ falls in a certain interval as indicated on the $y$ axis. Note that (f) is identical to (c) by construction; we show both here for clarity.

the warm, moist southerly flow and forming a steep moisture gradient over central China characteristic of the mei-yu front. The northerlies essentially disappear when the mei-yu ends, leading to the demise of the strong moisture contrast (Fig. 2). This view is in agreement with previous findings on the close connection between the mei-yu and cold air mass associated with northerlies (Li and Zhang 2014; Seo et al. 2015; Tomita et al. 2011). Park et al. (2012) found that the mei-yu is associated with southward low moist static energy (MSE) flux (integrated 
Jet@37N

(a)

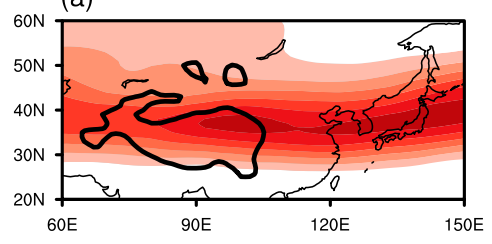

(d)

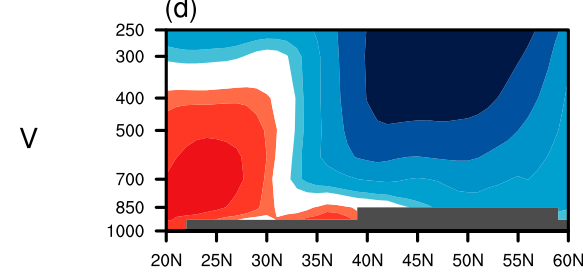

$20 \mathrm{~N} \quad 25 \mathrm{~N} \quad 30 \mathrm{~N} \quad 35 \mathrm{~N} \quad 40 \mathrm{~N} \quad 45 \mathrm{~N} \quad 50 \mathrm{~N}$ - $55 \mathrm{~N}$ -

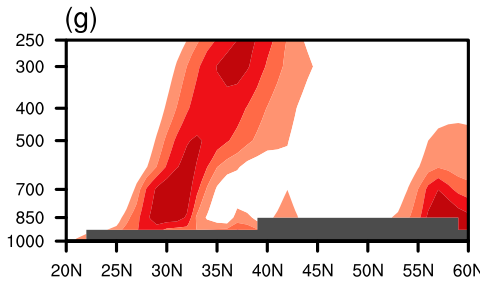

$20 \mathrm{~N} 25 \mathrm{~N} 30 \mathrm{~N} 35 \mathrm{~N} 40 \mathrm{~N} 45 \mathrm{~N} 50 \mathrm{~N} 55 \mathrm{~N} 60 \mathrm{~N}$

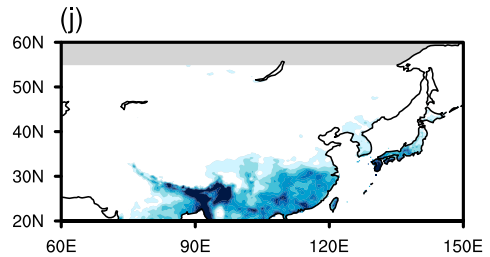

Jet@40N

(b)

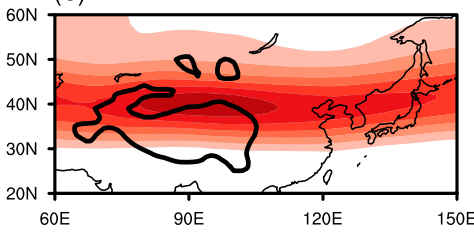

Jet@43N

(c)

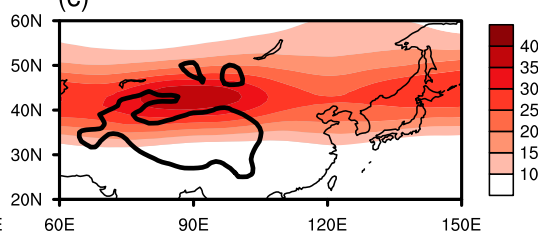

(e)

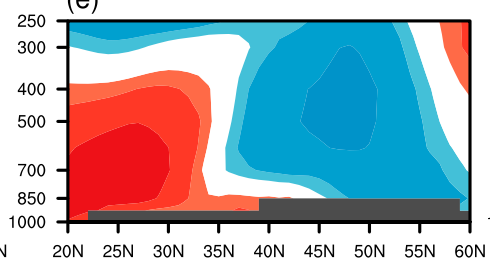

(h)

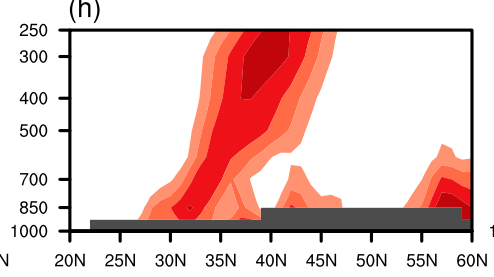

(k)

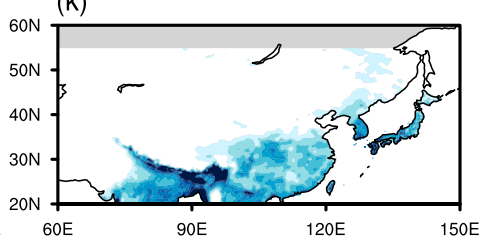

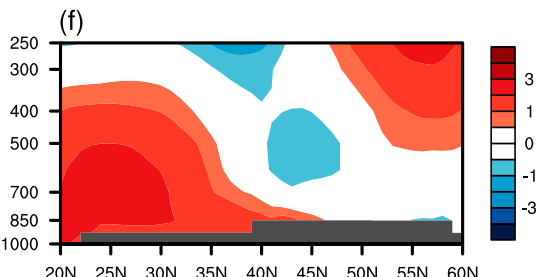
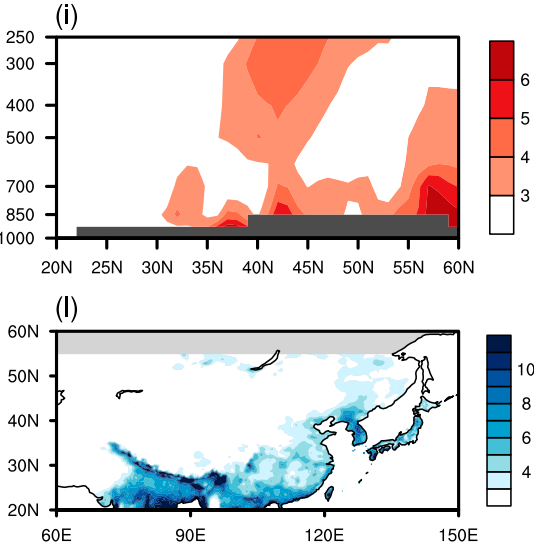

FIG. 7. Composites based on pentads when latitude of the zonal wind maximum impinging on the Tibetan Plateau is (left) $37^{\circ} \mathrm{N}$, (center) $40^{\circ} \mathrm{N}$, and (right) $43^{\circ} \mathrm{N}$. The pentads are taken from April through September, for years 1979-2007. (a)-(c) Zonal wind at $\left.200 \mathrm{mb}^{-6} \mathrm{~m} \mathrm{~s}^{-1}\right)$.

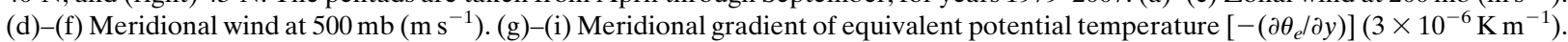
(j)-(l) APHRODITE rain gauge data $\left(\mathrm{mm} \mathrm{day}^{-1}\right)$. Black contours in (a)-(c) indicate an elevation of $2000 \mathrm{~m}$.

from the surface to $600 \mathrm{mb}$ ) over northeastern China and northward high MSE flux over southeastern China. In this vein, the mei-yu terminates when the southward low MSE air disappears with northerlies. Chou and Neelin (2003) argued that advection of low MSE air over the northern reaches of monsoon regions limits the northward extent of summer monsoons, through the so-called ventilation effect. In a similar vein, the advection of low MSE air by the northerly flow limits the northward extent of the rainfall over eastern China (Figs. 8a-c); as such, rainfall shifts to northeastern China in midsummer as the northerly flow retreats.

The northerlies are also crucial for the mei-yu formation through maintaining strong meridional wind convergence. Simulations with and without the Tibetan Plateau by Chen and Bordoni (2014) suggest that the presence of the Tibetan Plateau and the resultant orographic downstream meridional wind convergence is key to the formation of mei-yu. Figures $8 \mathrm{~d}-\mathrm{f}$ show that meridional wind convergence over central eastern China is indeed considerably stronger in the mei-yu than in midsummer. It is worth noting that seasonal variation of meridional wind convergence over central eastern China (Fig. 8d) resembles the rainfall seasonality (Fig. 1g), indicating close connection between the two. As will be shown in the next section $5 b$, weakening of the meridional wind convergence dominates the reduction of moisture flux convergence associated with mei-yu termination.

\section{b. Moisture budget analysis}

We explicitly show the role of meridional wind anomalies on rainfall changes associated with mei-yu termination through a vertically integrated moisture budget analysis. We follow Chen and Bordoni (2016) and employ moisture budget analysis to diagnose contributions to the moisture flux convergence. In long-term average, the moisture budget can be written as 
Hovmoller

(a)
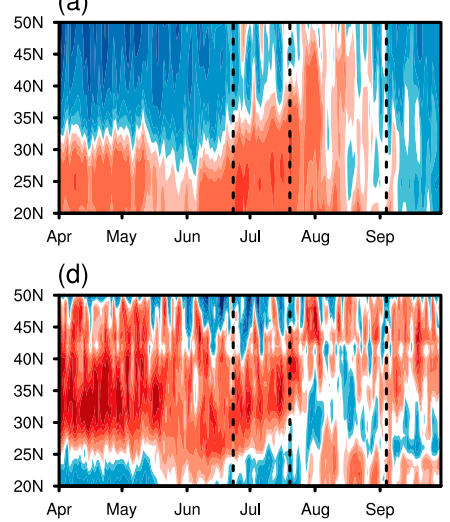

mei-yu - midsummer
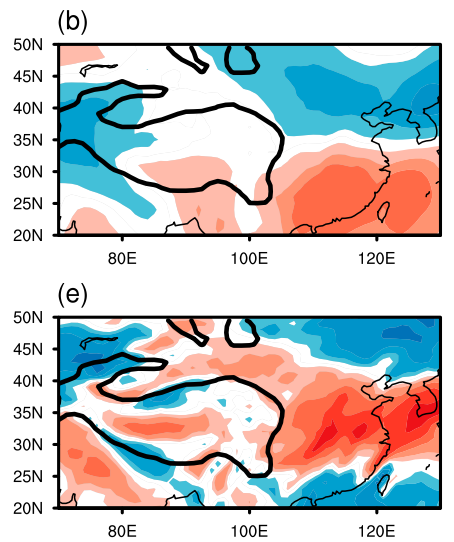

mei-yu - midsummer
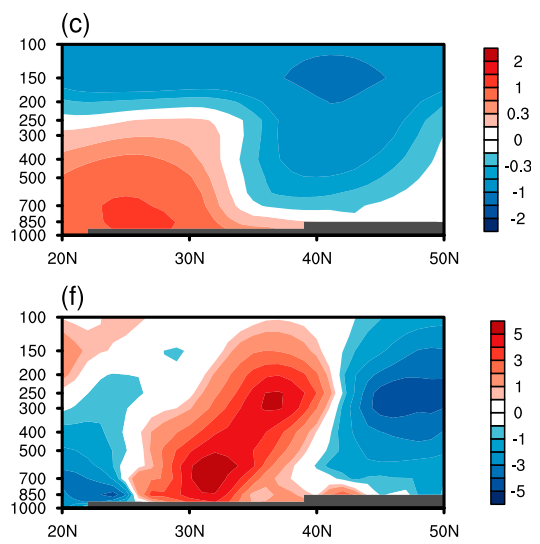

FIG. 8. (top) The meridional MSE flux $\left(v h ; h=C_{p} T+L_{v} q+g z\right)$ and (bottom) the meridional wind convergence [ $\left.-(\partial v / \partial y)\right]$. Results are shown for (a),(d) Hovmöller diagram of vertical integrations (1000-250 mb) averaged over $110^{\circ}-120^{\circ} \mathrm{E}$, (b), (e) differences of vertical integrations (1000-250 mb) between mei-yu and midsummer (mei-yu minus midsummer), and (c),(f) differences of averaged values over $110^{\circ}-120^{\circ} \mathrm{E}$ between mei-yu and midsummer (mei-yu minus midsummer). Units are $10^{6} \mathrm{~W} \mathrm{~m}^{-1}$ in (a) and (b), $10^{6} \mathrm{~W} \mathrm{~m} \mathrm{~s}{ }^{-1}$ in (c), $10^{-3} \mathrm{~kg}$ $\mathrm{m}^{-2} \mathrm{~s}^{-1}$ in (d) and (e), and $10^{-6} \mathrm{~s}^{-1}$ in (f). Gray shadings in (c) and (f) indicate zonally averaged topography over $110^{\circ}-120^{\circ} \mathrm{E}$. Black contours in (b) and (e) indicate an elevation of $2000 \mathrm{~m}$.

$$
\bar{P}-\bar{E}=-\overline{\langle\nabla \cdot(\mathbf{v} \cdot q)\rangle},
$$

where $P$ is precipitation, $E$ is evaporation, $\mathbf{v}$ indicates horizontal winds, and $q$ is specific humidity; $\overline{(\cdot)}$ indicates temporal mean, while $\langle\cdot\rangle$ indicates the mass-weighted vertical integral from 1000 to $100 \mathrm{mb}$. Contribution to the vertically integrated moisture flux convergence by submonthly transient eddies is calculated from

$$
\operatorname{trans}=\overline{\langle\nabla \cdot(\mathbf{v} \cdot q)\rangle}-\nabla \cdot(\overline{\mathbf{v}} \bar{q}) .
$$

Changes $(\delta)$ of vertically integrated moisture flux convergence between mei-yu and midsummer in climatology can be written as

$$
\begin{aligned}
\delta(\bar{P}-\bar{E}) & =-\delta\{\overline{\langle\nabla \cdot(\mathbf{v} \cdot q)\rangle}\} \\
& =-\delta\{\langle\nabla \cdot(\overline{\mathbf{v}} \bar{q})\rangle\}-\delta(\text { trans }),
\end{aligned}
$$

where $\delta$ indicates mei-yu minus midsummer. Equation (3) can be written as below by further decomposition of the term $-\delta\{\nabla \cdot(\overline{\mathbf{v}} \bar{q})\}$ :

$$
\begin{aligned}
-\delta\{\overline{\langle\overline{\langle\nabla \cdot(\mathbf{v} \cdot q)\rangle}\}}= & -\underbrace{\langle\nabla \cdot(\overline{\mathbf{v}} \cdot \delta \bar{q})\rangle}_{\mathrm{B}}-\underbrace{\langle\nabla \cdot(\delta \overline{\mathbf{v}} \cdot \bar{q})\rangle}_{\mathrm{C}} \\
& -\underbrace{\langle\nabla \cdot(\delta \overline{\mathbf{v}} \cdot \delta \bar{q})\rangle}_{\mathrm{D}}-\underbrace{\delta(\text { trans })}_{\mathrm{E}},
\end{aligned}
$$

where term A indicates changes of vertically integrated moisture flux convergence, term $\mathrm{B}$ is contribution by changes to the specific humidity, term $\mathrm{C}$ is contribution by changes to the horizontal winds, term $\mathrm{D}$ is contribution by changes to both specific humidity and horizontal winds, and term $\mathrm{E}$ is contribution by submonthly transients. Note that variables without $\delta$ in terms B and C represent midsummer. Seager and Henderson (2013) noted that the divergence of the vertically integrated moisture transport does not balance the ERA-Interim $P-E$, possibly from the influence of the data assimilation. We find slight difference between the magnitude of $\delta(P-E)$ and term A, but the patterns between the two match well (not shown).

Figures 9a-e shows terms A-E of Eq. (4), respectively, for the difference between the mei-yu and midsummer averages, in order to examine changes occurring to the components of the moisture flux budget between these intraseasonal stages. Not surprisingly, the mei-yu season exhibits enhanced moisture transport and moisture flux convergence over central eastern China (Fig. 9a). This enhancement is dominated by changes of horizontal winds (Fig. 9c), while the contribution by changes of specific humidity is minimal (Fig. 9b). Contributions by the crossperturbation term (Fig. 9d) and the submonthly transient eddies (Fig. 9e) are negligible. Decomposing contributions by the horizontal winds (Fig. 9c) to its zonal (Fig. 9f) and meridional components (Fig. 9g) indicates that changes in the meridional wind are essential to changes of the total moisture flux convergence. Contributions by the meridional winds could be further decomposed as follows: $-(\partial / \partial y)(\delta v q)=-(\partial \delta v / \partial y) q-\delta v(\partial q / \partial y)$, where $-(\partial \delta v / \partial y) q$ is contribution by changes in meridional wind convergence, while $-\delta v(\partial q / \partial y)$ is the contribution by changes in the meridional advection of moisture. Figures $9 \mathrm{~h}$ and $9 \mathrm{i}$ indicate that although both terms positively contribute to the moisture flux convergence, changes of meridional wind convergence play the dominant role. 
(a)

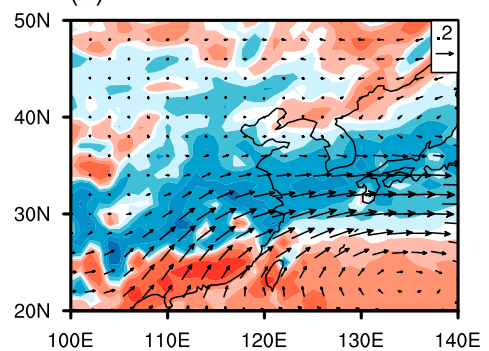

(d)

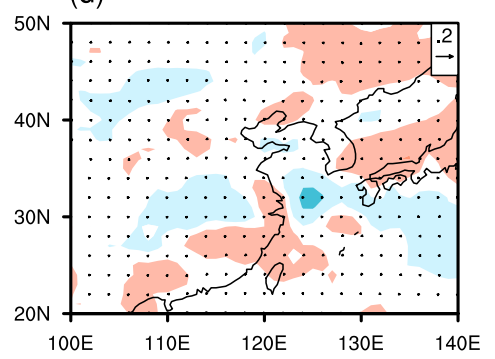

(g)

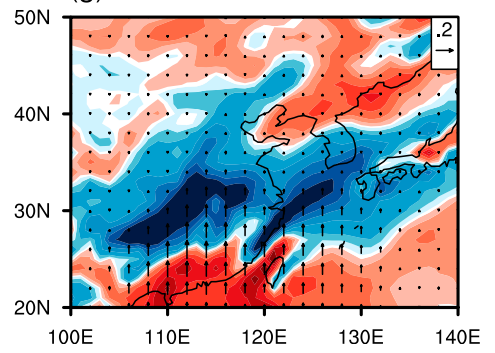

(b)

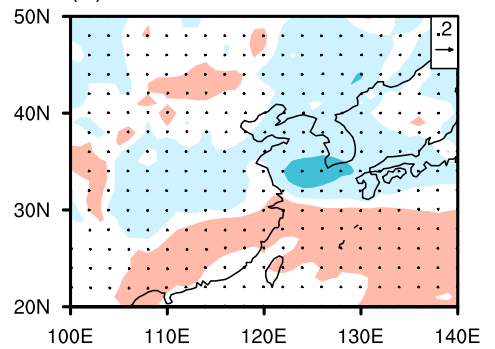

(e)

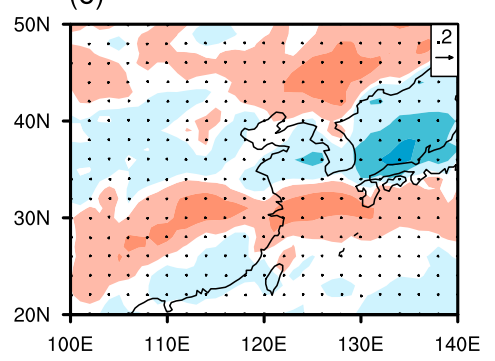

(h)

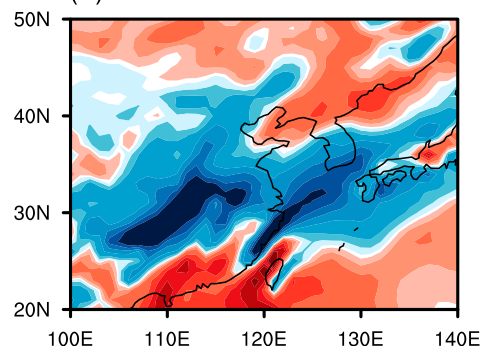

(c)
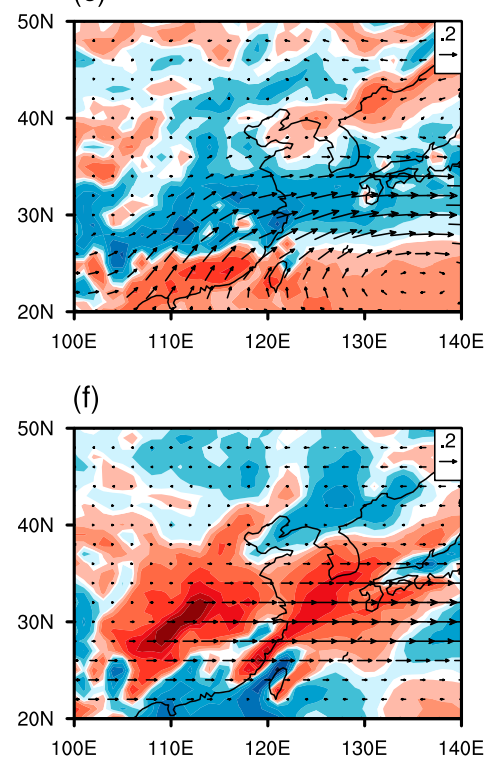

(i)

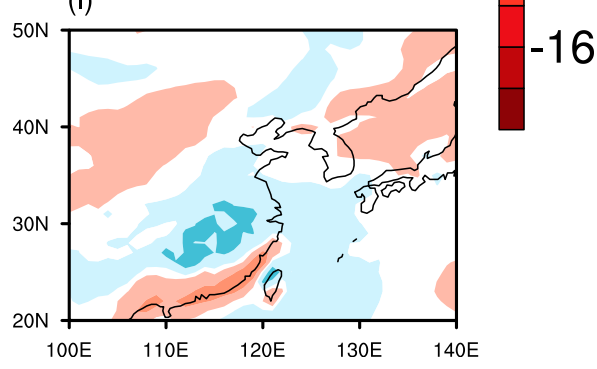

FIG. 9. Climatological changes in the mass-weighted vertical integral (from 1000 to $100 \mathrm{mb}$ ) of moisture budget components between mei-yu and midsummer (mei-yu minus midsummer). Vectors denote moisture fluxes $\left(\mathrm{m}^{2} \mathrm{~s}^{-1}\right)$, and color shadings denote moisture flux convergence ( $\mathrm{mm} \mathrm{day}^{-1}$; cold color indicates convergence, and warm color indicates divergence). (a) Changes of moisture flux and its convergence. (b) Contributions by the changes of specific humidity. (c) Contributions by changes of horizontal winds. (d) Contributions by changes of both specific humidity and horizontal winds. (e) Contributions by changes of transients. (f) Contributions by changes to the zonal moisture flux and its convergence. (g)-(i) Contributions by changes to the meridional moisture flux and its convergence; (g) is contributed from two terms, with (h) showing the contributions by meridional wind convergence and (i) showing contributions by meridional advection of moisture.

We repeat the above analysis but in the context of the tripole mode of East Asian rainfall interannual variability, using again the high and low year composites defined in section 4 ; we refer to changes $(\delta)$ as low years minus high years. We focus on the gap in the timings of mei-yu termination between high and low years (i.e., 3-23 July). During this period, high years are already in the midsummer stage, while low years are still in mei-yu. The results (Fig. 10) show strong qualitative similarity to the analysis of Fig. 9 for the difference between mei-yu and midsummer stages, and reinforce the conclusions drawn from Fig. 9. Figure 10a shows enhanced moisture flux convergence over central China in low years relative to high years. The resemblance among Figs. 10a, $10 \mathrm{c}, 10 \mathrm{~g}$, and $10 \mathrm{~h}$ highlight the crucial role of meridional wind convergence in changes of total moisture flux convergence during the period when high years are in midsummer while low years are still in mei-yu.

\section{c. Relative contributions from northerlies and southerlies}

The moisture budget analysis above clearly shows the central role of meridional wind changes in mei-yu termination. We have focused on the role of the extratropical northerlies, but one might argue that variations of the southerlies also contribute to the mei-yu termination. On average, southerlies over eastern China are indeed weaker in midsummer, although this weakening is mainly limited to south of $30^{\circ} \mathrm{N}$ (Figs. $4 \mathrm{~g}-\mathrm{j}$ ). Figure $9 \mathrm{~g}$ also suggests the southerly moisture flux dominates 
(a)

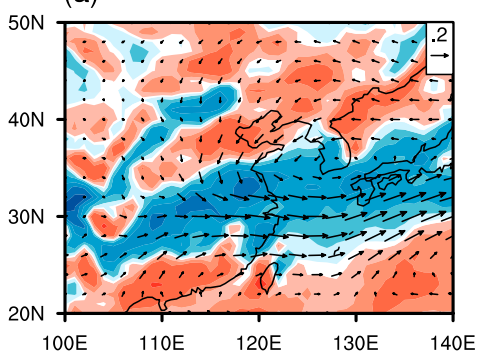

(d)

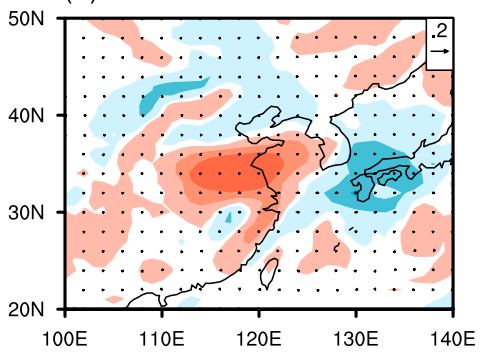

(g)

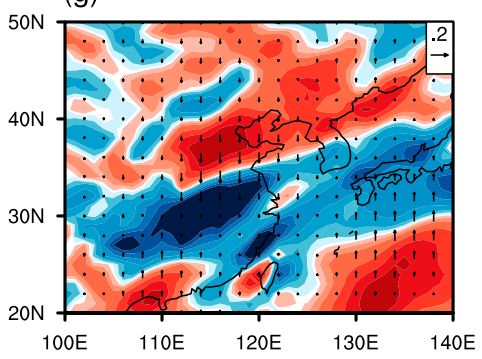

(b)

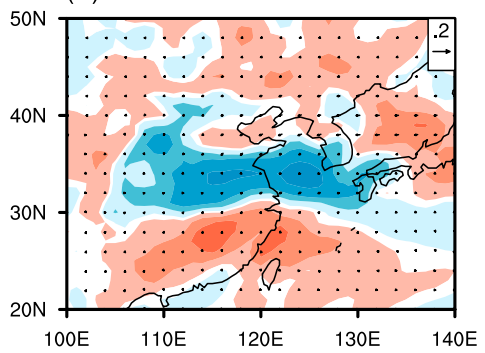

(e)

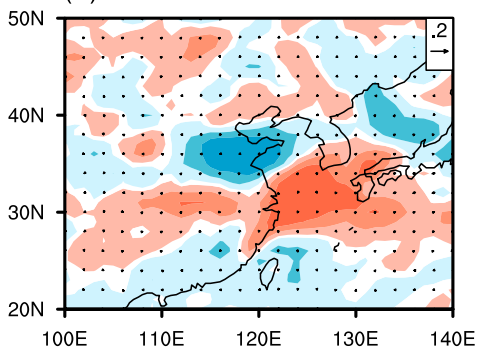

(h)

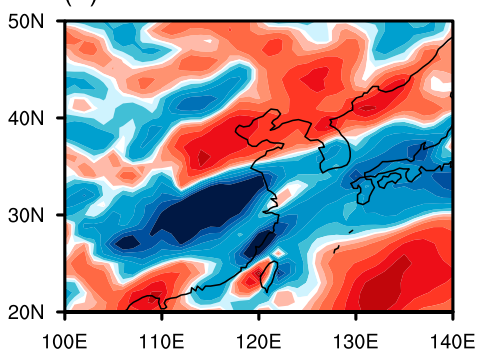

(c)

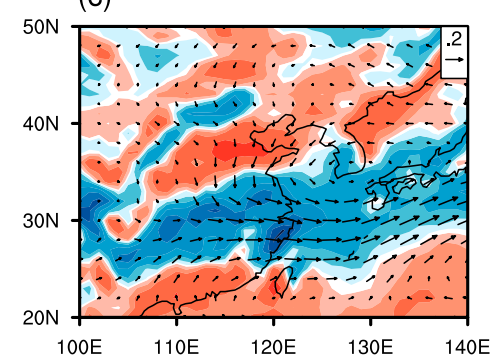

16
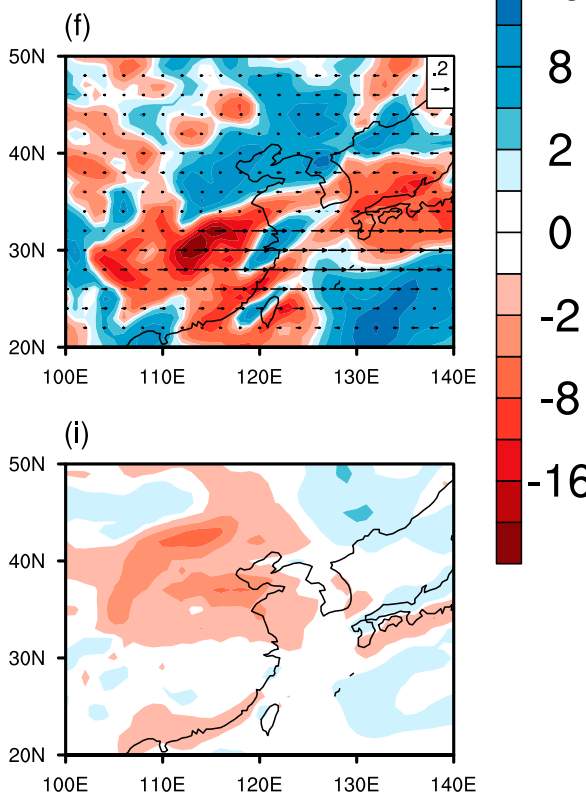

FIG. 10. As in Fig. 9, but for comparison between high years and low years from 3 Jul (timing of mei-yu termination in high years) to 23 Jul (timing of mei-yu termination in low years). Here, changes denote low years minus high years.

contribution to the enhanced moisture flux convergence in mei-yu. However, the moisture budget analysis is diagnostic, so the southerlies can be, in part, interpreted as a feedback. In particular, diabatic heating from the mei-yu rainband and consequent vortex stretching will lead to a southerly flow because of Sverdrup vorticity balance (Rodwell and Hoskins 2001). Furthermore, Fig. 4f shows that the most striking change in the meridional circulation associated with the mei-yu termination is disappearance of extratropical northerlies and northward penetration of southerlies. It suggests that weakening of the northerlies is the root cause of the transition from mei-yu to midsummer.

On shorter time scales, Fig. 10 suggests stronger and more persistent southward moisture flux, associated with enhanced northerlies, dominates the enhanced moisture flux convergence in low years during 3-23 July. Further, our composites of meridional wind at pentads with different jet positions clearly show the weakening of extratropical northerlies when the jet is located north of the plateau (Figs. 7d-f). However, there is no evident change in the strength of tropical southerlies among these composites.

We note in closing that relative roles of tropical southerlies and extratropical northerlies are still in debate. A recent idealized study by Son et al. (2019) suggests that orographic downstream southerlies are most crucial for the EASM. Tomita et al. (2011) and Suzuki and Hoskins (2009) suggest that the closing dates of baiu (the Japanese sector of the mei-yu-baiu rain belt) could be modified by the combined effects of both tropical and midlatitude circulations.

\section{Termination of the mei-yu with a northward- extended Tibetan Plateau}

Based on the various lines of evidence presented in sections 3-5, we propose this hypothesis on the mei-yu termination: the weakening and eventual disappearance of the northerlies over northeastern China leads to the 
Plateau control

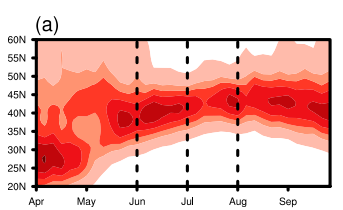

v
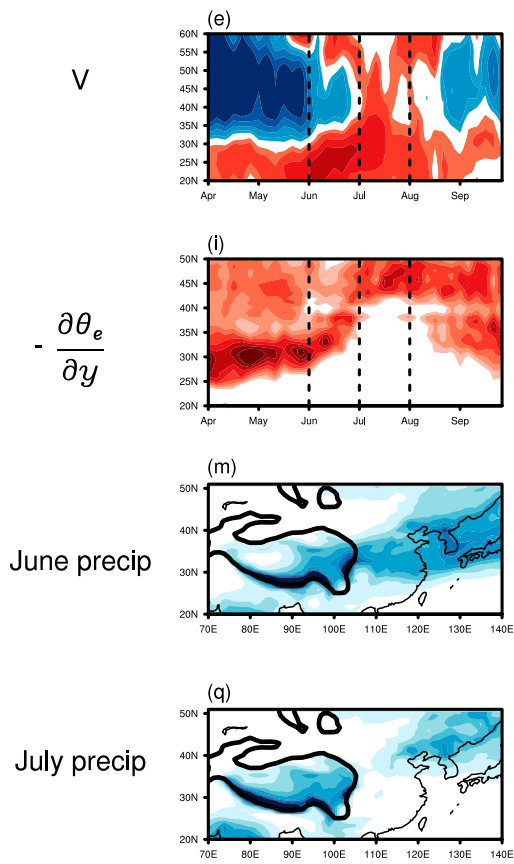

Plateau_3deg
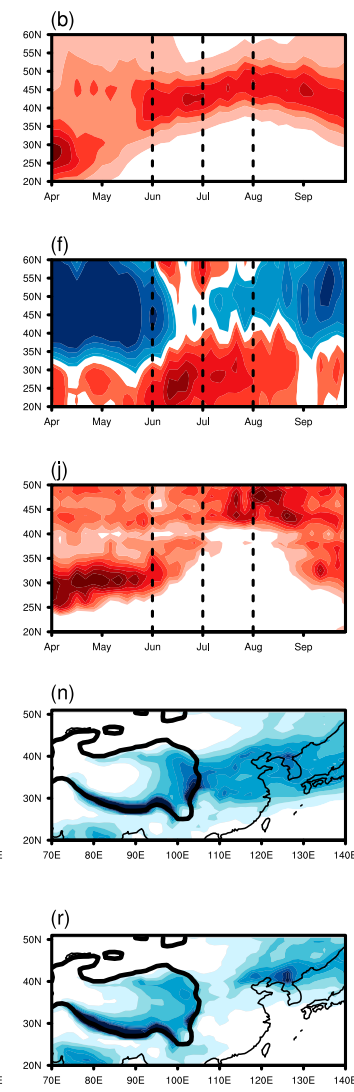

Plateau_6deg
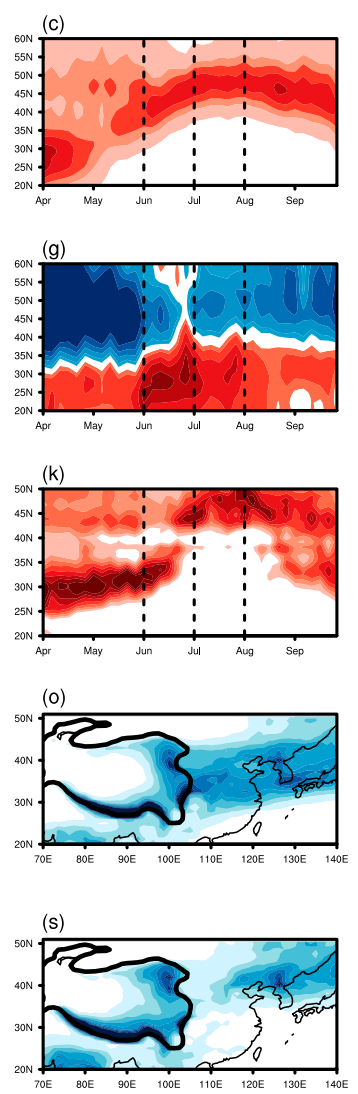

Plateau_10deg
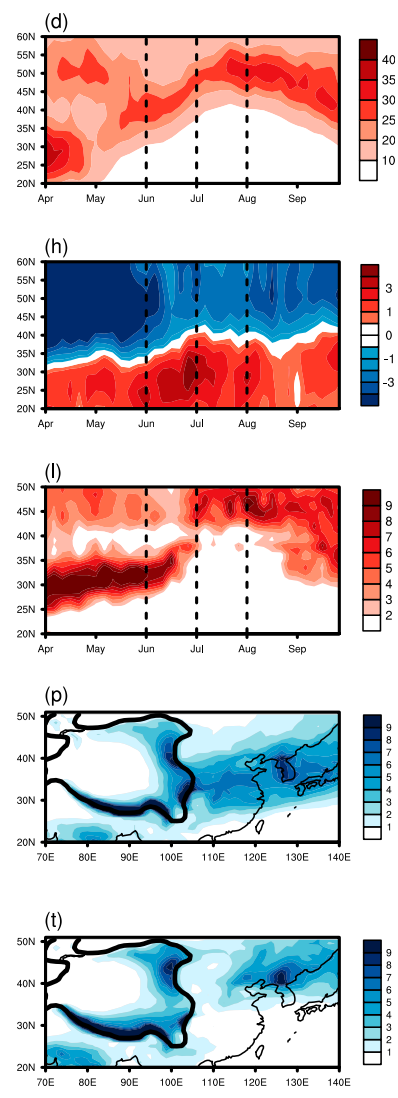

FIG. 11. Results from (first column) the Plateau_control, (second column) Plateau_3deg, (third column) Plateau_6deg, and (fourth column) Plateau_10deg simulations. Hovmöller diagram of (a)-(d) zonal wind at $200 \mathrm{mb}$ averaged over $80^{\circ}-100^{\circ} \mathrm{E}$ and (e)-(h) meridional wind at $500 \mathrm{mb}$ averaged over $110^{\circ}-120^{\circ} \mathrm{E}\left(\mathrm{m} \mathrm{s}^{-1}\right)$. (i)-(l) Hovmöller diagram of meridional gradient of $\theta_{e}$ at $850 \mathrm{mb}$ and over $110^{\circ}-120^{\circ} \mathrm{E}$ $\left(3 \times 10^{-6} \mathrm{~K} \mathrm{~m}^{-1}\right)$. Large-scale precipitation averaged in $(\mathrm{m})-(\mathrm{p})$ June and in $(\mathrm{q})-(\mathrm{t})$ July $\left(\mathrm{mm} \mathrm{day}^{-1}\right)$. Black contours in $(\mathrm{m})-(\mathrm{t})$ indicate an elevation of $2000 \mathrm{~m}$.

demise of the mei-yu, and this weakening is a direct consequence of the northward shift of westerlies beyond the northern edge of the plateau, around $40^{\circ} \mathrm{N}$. We speculate that the reduced orographic forcing on the westerlies during the northward jet transition causes the weakening of the orographic downstream northerlies.

To test this hypothesis, we artificially perturb the orographic forcing of the Tibetan Plateau by changing the latitude of the northernmost edge of the plateau in the Community Atmosphere Model version 5 (CAM5). The expectation here is that with a more northward-extended plateau, mechanical forcing of the plateau on the westerlies should strengthen; by our hypothesis, northerlies downstream of the plateau should stay strong and mei-yu-like conditions persist as a result.

Figures $11 \mathrm{a}-\mathrm{d}$ present the simulated seasonal evolution of $200-\mathrm{mb}$ zonal wind over the plateau. With the presence of more northward-extended plateau, the westerlies impinging over the plateau are able to migrate to higher latitudes while the strength of the westerlies becomes weaker. In agreement with observations (Fig. 4f), tropospheric northerlies over northeastern China disappear from late June to late August in the Plateau_control run (Fig. 11e). Note that the simulated disappearance of northerlies occurs earlier (late June) than the observations (late July as suggested in Fig. 4f), indicating some model bias. Our hypothesis predicts stronger and more persistent northerlies downstream of the plateau as orographic forcing strengthens. When the plateau extends northward by $3^{\circ}$ and $6^{\circ}$, downstream northerlies indeed persist longer, with the disappearance of northerlies occurring over a shorter time period (Figs. 11f,g). When the plateau extends northward by $10^{\circ}$, northerlies prevail over northeastern China throughout the summer season, though weakening of northerlies is still notable from late June to August (Fig. 11h). 
Given the intensified northerlies (Figs. 11e-h) and meridional convergence (not shown), does the mei-yu front persist for longer duration in wider plateau scenarios? Note that due to the changed dimension of the plateau, the geographic location of the mei-yu in wider plateau cases may differ from the typical mei-yu in the present day. We thus identify the mei-yu front based on its expressed physical characteristics (i.e., sharp meridional gradients in $\theta_{e}$ ). Compared with the control run, the meridional gradient of $\theta_{e}$ becomes stronger from April through June over central eastern China when the plateau extends northward by $6^{\circ}$ and $10^{\circ}$ (Figs. 11i-1). The relatively weak gradient of $\theta_{e}$ in the Plateau_3deg case is consistent with disappearance of northerlies in mid- to late June (Figs. 11f,j). In July, southerlies occupy central to northeastern China in the control run, while northerlies prevail over the region in the wider plateau scenarios. As a result, Figs. 11i-1 show that the July meridional gradient of $\theta_{e}$ is more pronounced over northeastern China $\left(40^{\circ}-45^{\circ} \mathrm{N}, 110^{\circ}-120^{\circ} \mathrm{E}\right)$ in the wider plateau scenarios than in the control run. This suggests that the wider plateau cases are able to maintain the mei-yu-like front over northeastern China in July.

Additionally, summer rainfall over East Asia could be partitioned into "banded" rainfall, which is associated with large-scale frontal convergence, and "local" rainfall, which is possibly driven by local buoyancy or topography (Day et al. 2018). Day et al. (2018) suggest that banded rainfall constitutes the majority of precipitation during pre-mei-yu and mei-yu, while midsummer is mainly characterized by sporadic local rainfall. We view the existence of banded large-scale rainfall as an indicator of mei-yu-like rainfall. Therefore, we expect more pronounced mei-yu-like rainbands over northeastern China in July in the wider plateau simulations. To estimate the amount of banded rainfall, we examine the large-scale rainfall from the model output. ${ }^{2}$ When northerlies over northeastern China are stronger and more persistent, large-scale rainfall over eastern China should be intensified as well. Figures $11 \mathrm{~m}-\mathrm{p}$ and $11 \mathrm{q}-\mathrm{t}$ show the spatial distribution of large-scale rainfall in June and July, respectively. The leftmost panel suggests that the banded structure of rainfall in the control run is pronounced in June but disappears in July. In contrast, the rainbands remain in the wider plateau cases in July, though with weaker magnitude and more northward location.

\footnotetext{
${ }^{2}$ Here, large-scale rainfall is rainfall from large-scale circulation that can be resolved by the model resolution, while convective rainfall is parameterized based on the Zhang-McFarlane scheme (Zhang and McFarlane 1995).
}

One caveat to the "northward extended plateau" simulations is that it is difficult to exclude the potential role of diabatic heating over the plateau on the changes in the circulation and rainfall over East Asia (e.g., Li and Yanai 1996; Wu et al. 2012). Future studies are required to fully understand the relative contribution of the mechanical and thermal forcing of the Tibetan Plateau on the evolution of the EASM.

\section{Response of downstream northerlies to the positioning of the jet in a dry dynamical core simulation}

In this section, we use the dry dynamical core from CAM5 to further show that the downstream northerlies can originate from mechanical forcing on the westerlies by the Tibetan Plateau, and that the northerlies disappear when the westerlies impinging on the plateau shift sufficiently northward of it. The idealized physics of the dry dynamical core (see section 2d) allows us to neglect possible effects of moisture feedbacks and diabatic heating on the westerlies. We relax the model to the same equilibrium radiative temperature profile in all cases, and perturb the relative positioning between westerlies and the plateau by shifting the plateau meridionally in order to mimic the northward seasonal migration of the westerlies.

\section{a. Results}

Figure 12 shows the zonal winds and meridional winds from the idealized simulations. When the plateau is shifted northward by $6^{\circ}$ (PlateauN6; Figs. 12a,k), the configuration of westerlies around the plateau resembles spring in observations, with a much stronger southern branch of westerly wind to the south of the plateau compared with its counterpart to the north. In contrast to PlateauN6, the southern branch of westerlies in the PlateauN3 scenario is weaker, while the northern branch is stronger (Figs. 12b,l). The northern branch becomes further pronounced when the plateau is at the modernday location (Figs. 12c,m). The westerlies are well north of the topography when the plateau is shifted to the south (Figs. 12d,e,n,o). In short, these scenarios mimic the northward seasonal migration of westerlies relative to the Tibetan Plateau from spring to summer. The responses of orographic downstream northerlies to perturbations of relative positioning between westerlies and the plateau are not clear-cut monotonic (Figs. 12f-j, p-t). However, the simulations demonstrate that the orographic downstream northerlies exhibit general weakening as location of westerlies changes from south of the plateau to north (Figs. $12 \mathrm{f}-\mathrm{j}, \mathrm{p}-\mathrm{t}$ ). It is also worth noting that the downstream southerlies strengthen as the core of the westerlies 
PlateauN6
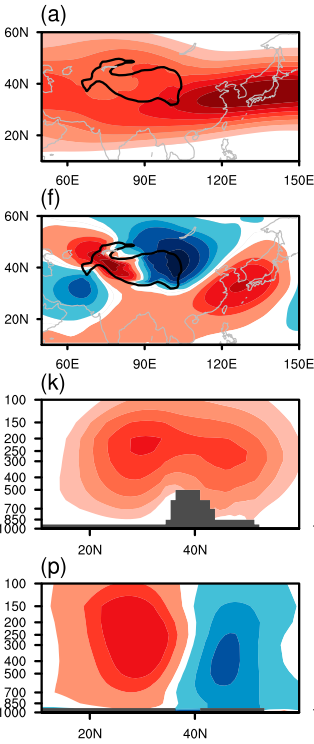

PlateauN3
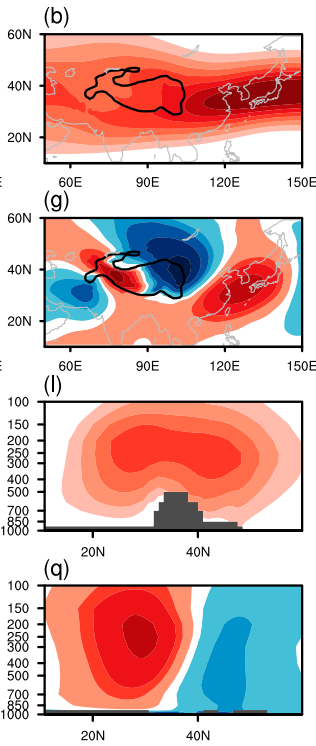

Plateau
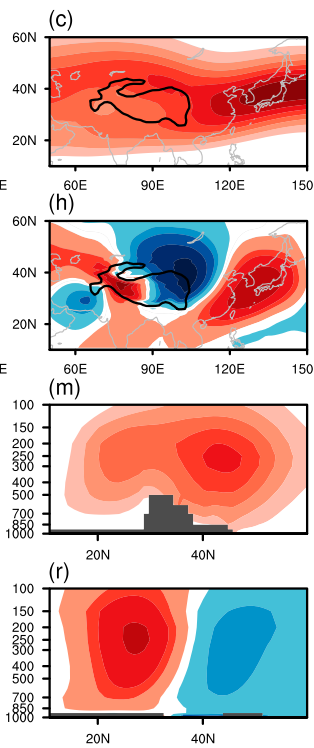

PlateauS3
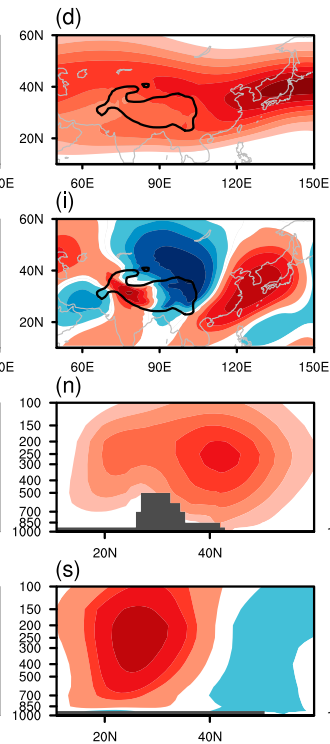

PlateauS6
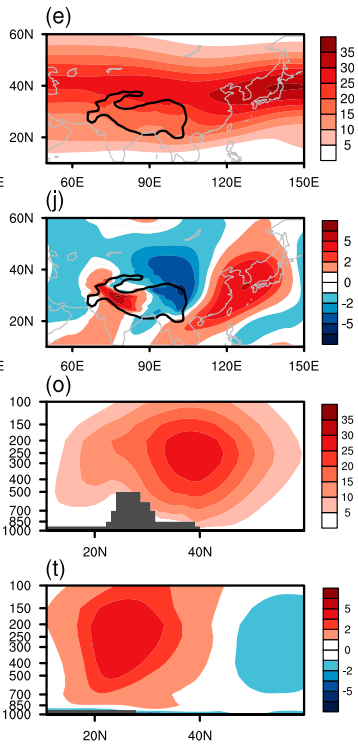

FIG. 12. Results from the dry dynamical core simulations (from left to right) PlateauN6, PlateauN3, Plateau, PlateauS3, and PlateauS6. (a)-(e) Zonal wind at $200 \mathrm{mb}$. (f)-(j) Meridional wind at $500 \mathrm{mb}$. (k)-(o) Zonal wind averaged over $80^{\circ}-100^{\circ} \mathrm{E}$; (p)-(t) Meridional wind averaged over $110^{\circ}-120^{\circ} \mathrm{E}$. Black contours in (a)-(j) indicate an elevation of $2000 \mathrm{~m}$.

shifts from being south of the plateau to north of it (Figs. $12 \mathrm{f}-\mathrm{j}, \mathrm{p}-\mathrm{t}$ ).

\section{b. Mechanism revealed in the dry dynamical core simulations}

The low eddy geopotential height anomaly at $500 \mathrm{mb}$ to the east of the orography appears to be a dynamical consequence of the orographic forcing on the atmosphere (Bolin 1950; Charney and Eliassen 1949; Held 1983) (the eddy geopotential height is defined as the geopotential height with the global zonal mean of geopotential height subtracted). We use the variation of eddy geopotential height at $500 \mathrm{mb}$ downstream of the plateau as an indicator of changes in orographically forced stationary waves. In our idealized simulations, the simulations Plateau to PlateauS6 are the closest analogs to the seasonal shift of the jet to the north of $40^{\circ} \mathrm{N}$ in the real world, showing a weakening of orographic downstream northerlies from the former to the latter (Fig. 12). We show the eddy geopotential height at $500 \mathrm{mb}$ from these simulations in Figs. 13a-c. Weakening of the orographic downstream cyclonic circulation from Plateau to PlateauS6 is evident, suggesting that the weakening of the mechanical forcing by the plateau as the jet shifts northward is the primary cause of the weakening of northerlies.

Lutsko and Held (2016) examined the transition from zonal to meridional propagation of orographically induced stationary waves by varying the height of the orography. They found that the stationary wave response is meridionally trapped, zonally propagating for weaker orographic forcing (i.e., lower orography altitude). When the forcing is increased, the wave propagates more meridionally and more into the tropics. We find similar behavior in our simulations. When the westerlies are impinging on the plateau, the orographic downstream stationary waves propagate equatorward. As the plateau is moved to the south, the orographic forcing weakens and the propagation of the stationary waves becomes more zonal. Figures $13 \mathrm{~d}-\mathrm{f}$ present the quasigeostrophic eddy streamfunction and the horizontal Eliassen-Palm (EP) flux [Plumb 1985, Eq. (5.7) therein] at $250 \mathrm{mb}$. Following Lutsko and Held (2016), we show the ratio of the meridional component to the zonal component of the EP flux at $250 \mathrm{mb}$ averaged over $25^{\circ}-45^{\circ} \mathrm{N}, 100^{\circ}-150^{\circ} \mathrm{E}$ (highlighted with green dashed lines in Figs. 13d-f) in Fig. 13g. As positioning of the westerlies changes from south of the plateau to the north, the direction of the horizontal wave propagation downstream of the plateau becomes more zonal, and the eddy streamfunction weakens (Figs. 13d-f), further indicating reduced orographic forcing as the jet shifts to north of the plateau.

Taken together, when the westerlies shift to the north of the plateau, orographic forcing on the westerlies weakens, leading to reduced cyclonic circulation downstream of the plateau. Weakening of the cyclonic circulation in turn weakens the northerlies downstream of the topography. 

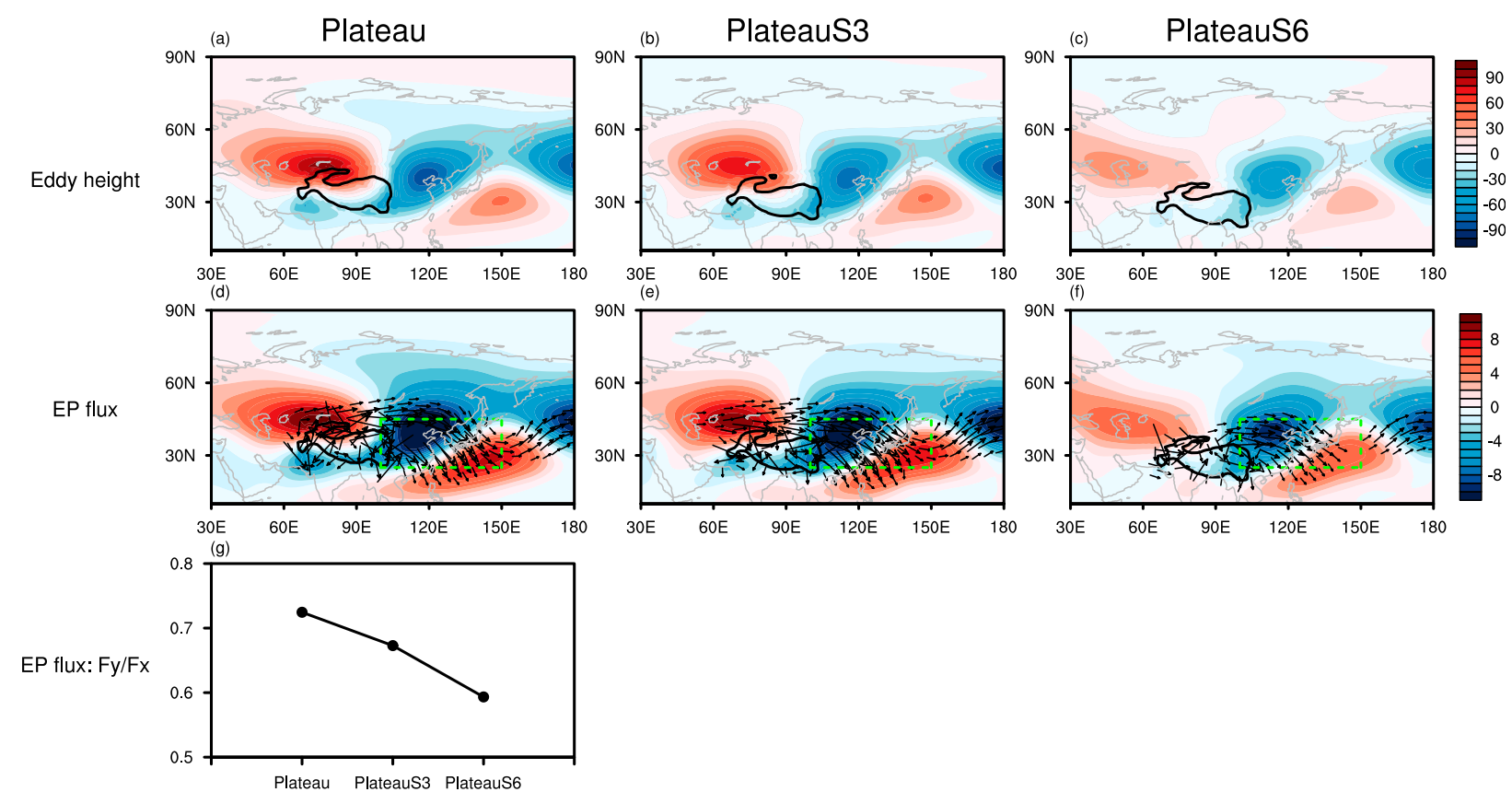

FIG. 13. (top) Eddy geopotential height at $500 \mathrm{mb}(\mathrm{m})$ and (bottom) horizontal EP flux (vectors; $\mathrm{m}^{2} \mathrm{~s}^{-2}$ ) and quasigeostrophic eddy streamfunction (color shading; $10^{6} \mathrm{~s}^{-1}$ ) at $250 \mathrm{mb}$ from the idealized simulations (a),(d) Plateau, (b), (e) PlateauS3, and (c),(f) PlateauS6. (g) The ratio of the meridional component of the EP flux to the zonal component of the EP flux at 250 mb averaged over $25^{\circ}-45^{\circ} \mathrm{N}, 100^{\circ}-$ $150^{\circ} \mathrm{E}$. Black solid lines in (a)-(f) denote imposed topography and indicate elevation of $2000 \mathrm{~m}$. Green dashed lines in (d)-(f) denote the area used for the calculation of $(\mathrm{g})$.

\section{c. Weakening of the downstream cyclonic circulation in observations}

Now we discuss to what extent the mechanism revealed in the dry dynamical core simulations is seen in the observed mei-yu termination. Resembling the dry dynamical core runs (Figs. 13a-c), Fig. 14 shows weakening of the cyclonic circulation over northeastern China from mei-yu to midsummer. Figure 15 shows Hovmöller diagrams of eddy geopotential height $Z^{\prime}$ at 200 and $500 \mathrm{mb}$ averaged over $110^{\circ}-150^{\circ} \mathrm{E}$ (denoted by dashed lines in Fig. 14) for climatology of 1979-2007 (Figs. 15a,d), and for composites of high years (Figs. 15b,e) and low years (Figs. 15c,f) over 1979-2007. Here, the high and low years are selected based on the PC1 of July-August rainfall over East Asia (Chiang et al. 2017) (see section 4). The eddy geopotential height at $200 \mathrm{mb}$ changes from negative values to positive values during mei-yu termination in all three cases, and indicates a transition from cyclonic to anticyclonic circulation in the upper troposphere (Figs. 15a-c). The anticyclonic circulation exists throughout the midsummer stage, and reverts back to a cyclonic circulation when midsummer ends. In agreement with Fig. 14, the eddy geopotential height at $500 \mathrm{mb}$ also represents an abrupt weakening of the cyclonic circulation (Figs. 15d-f). These results support our interpretation that weakening
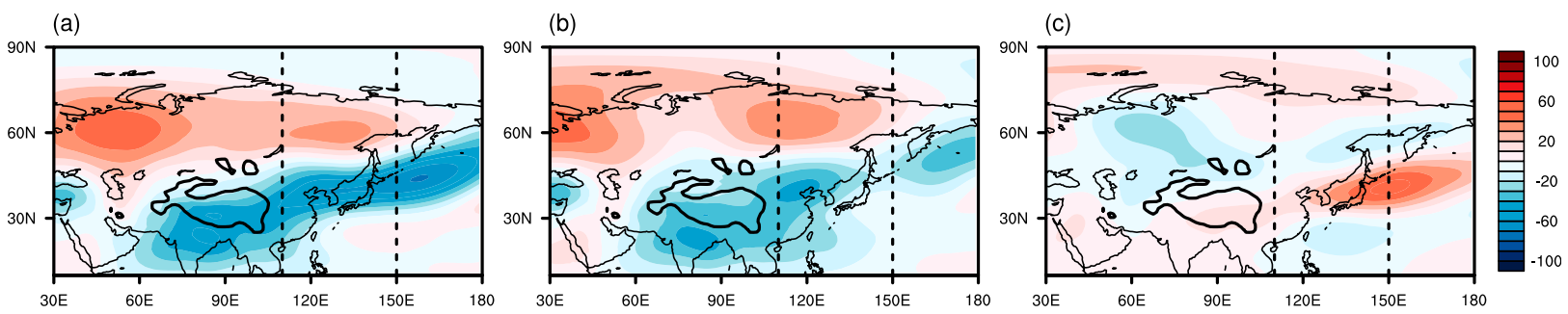

FIG. 14. Eddy geopotential height at $500 \mathrm{mb}(\mathrm{m}$ ) over 1979-2007 during (a) mei-yu, (b) midsummer, and (c) midsummer minus mei-yu. Timing of mei-yu and midsummer is determined by the SOM analysis. Dashed lines indicate the longitudinal range used for the zonal average shown in Fig. 15. Black contours indicate an elevation of $2000 \mathrm{~m}$. 
(a) $c \lim 200 \mathrm{mb}$

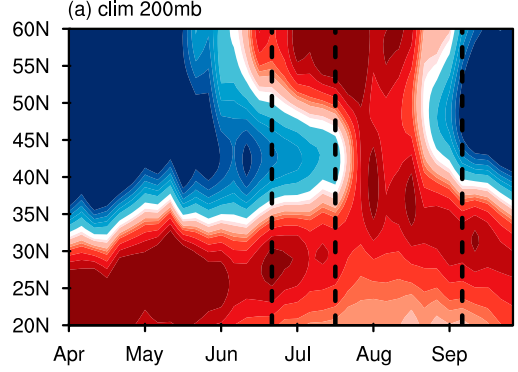

(d) $\operatorname{clim} 500 \mathrm{mb}$

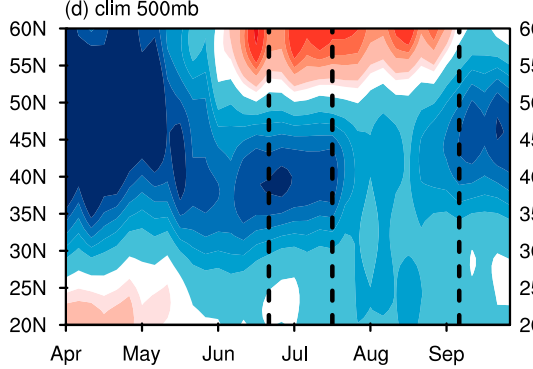

(b) high $200 \mathrm{mb}$

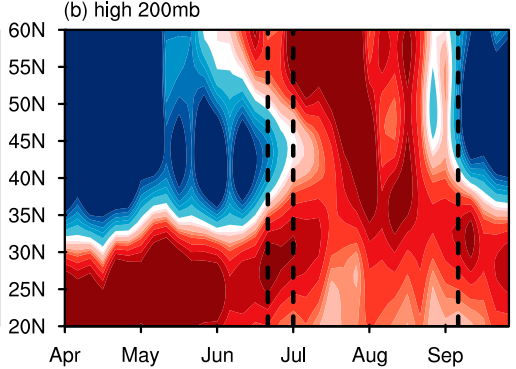

(e) high $500 \mathrm{mb}$

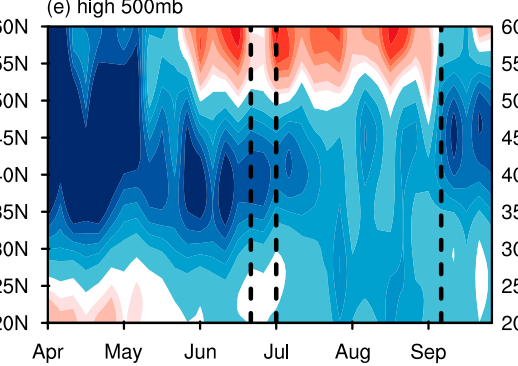

(c) low $200 \mathrm{mb}$

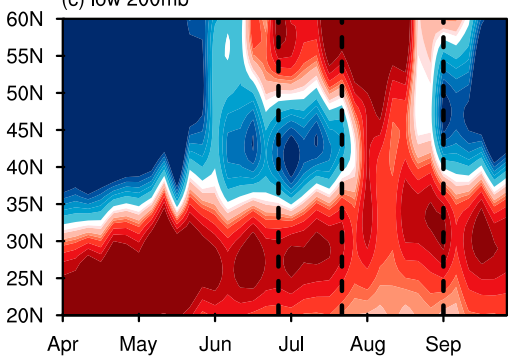

(f) low $500 \mathrm{mb}$

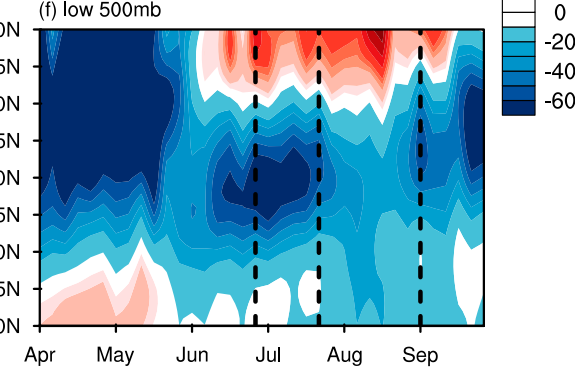

FIG. 15. Hovmöller diagram of eddy geopotential height averaged over $110^{\circ}-150^{\circ} \mathrm{E}$ at (a)-(c) $200 \mathrm{mb}$ and at (d)-(f) $500 \mathrm{mb}$ for (left) 1979-2007 climatology, (center) high year climatology, and (right) low year climatology. Black dashed lines in (a)-(f) demarcate pre-meiyu, mei-yu, midsummer, and end periods, respectively.

of the tropospheric cyclonic circulation leads to disappearance of the northerlies.

\section{Summary}

This study investigates how changes in the meridional position of the westerly jet impinging over the Tibetan Plateau affect termination of the mei-yu stage of the East Asian summer monsoon. Specifically, we ask whether there is a threshold in terms of the jet latitude over the Tibetan Plateau that controls the mei-yu termination.

In agreement with Kong et al. (2017) and Molnar et al. (2010), we show that the mei-yu termination in the climatology is accompanied by the northward migration of the jet axis away from the northern edge of the Tibetan Plateau at $40^{\circ} \mathrm{N}$. Concurrently, tropospheric northerlies over northeastern China weaken during the mei-yu and disappear when the mei-yu ends. Further examinations suggest that the close linkage between transit of jet axis beyond the northern edge of the plateau, weakening of downstream northerlies, and mei-yu termination also holds on interannual time scales. As westerlies exhibit large meridional excursions on synoptic time scales, we then examine whether the above connection holds on shorter (i.e., pentad) time scales. We found that the jet axis ranges between $38^{\circ}$ to $41^{\circ} \mathrm{N}$ for mei-yu-like pentads, while midsummer-like pentads are associated with the jet axis between $40^{\circ}$ to $43^{\circ} \mathrm{N}$. Furthermore, northeastern China $\left(110^{\circ}-120^{\circ} \mathrm{E}, 35^{\circ}-40^{\circ} \mathrm{N}\right)$ exhibits strong northerly wind during mei-yu-like pentads, while the northerly wind almost disappears among midsummer-like pentads.
We argue that the reduction of the northerlies is causally linked to the demise of mei-yu through the following processes. First, reduction of the northerlies leads to weakening of the meridional contrast of equivalent potential temperature over central China, which is crucial for the maintenance of the mei-yu front ( $\mathrm{Li}$ and Lu 2017; Park et al. 2012). Furthermore, invoking the "ventilation effect" (Chou and Neelin 2003), strong northerlies over northern China during the mei-yu limit the northward extension of the rainband by southward advection of low MSE air; when northerlies disappear, the ventilation effect is gone and rainfall extends to northeastern China in midsummer. Last, the disappearance of northerlies weakens the meridional wind convergence. Moisture budget analyses show that the significant reduction of total moisture flux convergence over central eastern China from mei-yu to midsummer is mainly due to weakening of meridional wind convergence.

We argue that weakening of orographic downstream northerlies is caused by reduced orographic forcing on the westerlies as the jet migrates beyond the plateau. To test this, we perform idealized simulations with CAM5 where the northern edge of the plateau is artificially extended northward, the idea being that orographic forcing should strengthen and thus the mei-yu should terminate later in such cases. The simulated results support our predictions. With the northern edge of the plateau extended northward, northerlies become more persistent, stronger, and the mei-yu-like (i.e., banded) rainfall regime becomes more pronounced over northeastern China. Several paleoclimate studies suggest that the uplift of the northern 
Tibetan Plateau intensifies the EASM (Baldwin and Vecchi 2016; Tang et al. 2013; Zhang et al. 2012), which is qualitatively consistent with results from our wider plateau simulations. However, the mechanisms proposed by these studies are different from ours. Zhang et al. (2012) links the intensification of the EASM to westward extension of the western Pacific subtropical high with the uplift of the northern Tibetan Plateau, while Tang et al. (2013) and Baldwin and Vecchi (2016) invoke the thermal effect of the northern plateau on the EASM. Further studies are needed to elucidate how changes in the mechanical forcing of the plateau have contributed to the past evolution of the EASM.

To further explore the mechanical origins of the downstream circulation response to plateau topography, we employ a dry dynamical core with a plateaulike feature embedded in the core of the simulated westerlies. We artificially perturb the relative positioning between westerlies and the plateau by shifting the plateau meridionally. Similar to observations, we found that the orographic downstream northerlies weaken as positioning of the jet relative to the plateau changes from south to north. These simulations highlight the importance of the mechanistic influence of the Tibetan Plateau on the downstream northerlies and hence on the termination of the mei-yu. This is in agreement with the results of Takahashi and Battisti (2007) (see Fig. 7 of Molnar et al. 2010). They successfully simulated a mei-yu-like front in an aquaplanet configuration that excludes the land-ocean thermal contrast and retains the mechanical interplay between the westerly jet and the Tibetan Plateau. We interpret the weakening of the orographic downstream northerlies to reflect changes in the orographically forced stationary waves. As westerlies migrate beyond the plateau, the cyclonic circulation to the east of the plateau weakens. Additional diagnostics show that the quasigeostrophic eddy streamfunction is reduced and the propagation of the orographic downstream stationary waves becomes more zonal. These results suggest weakening of the orographic forcing on the westerlies when the westerlies are north of the plateau. Finally, we examine the observational data to see if the mechanisms inferred from the idealized simulations occur in the observed mei-yu termination. We find that mei-yu termination is indeed accompanied by a weakening of the cyclonic circulation at $500 \mathrm{mb}$ downstream of the plateau, indicating weakening of the orographic forcing.

In short, the above findings suggest that the northern edge of the Tibetan Plateau at $40^{\circ} \mathrm{N}$ acts as a latitudinal threshold for jet position that triggers the termination of the mei-yu. The northerlies over northeastern China disappear as the jet axis over the plateau migrates north of $40^{\circ} \mathrm{N}$, and which in turn shuts off the meridional circulation maintaining the mei-yu front and terminates the mei-yu. This view supports the speculation by Molnar et al. (2010), who argues for the crucial role of the mechanical effects of the Tibetan Plateau on the modulation of mei-yu.

Fundamental questions remain. Here we have only considered the role of the meridional position of the westerlies impinging over the plateau on the termination of the mei-yu. Although the results appear to support our speculation that $40^{\circ} \mathrm{N}$ is the threshold of jet latitude that terminates the mei-yu, other characteristics of the westerlies could play a role. Recent studies have proposed connections between rainfall over the Yangtze River basin with various characteristics of westerlies, such as the zonal variation of the jet center (Xie et al. 2015), the intensity of the jet (Wang and Zuo 2016), and different configurations of the subtropical jet and polar front jet (Huang et al. 2014; Li and Zhang 2014). Additionally, though this study focuses on the role of the mechanical interaction between the westerlies and the Tibetan Plateau on the termination of the mei-yu, we cannot yet exclude other interpretations such as the influence of midtropospheric warm advection (Kosaka et al. 2011; Kuwano-Yoshida et al. 2013; Sampe and Xie 2010) and the role of surface heating over the Tibetan Plateau on East Asian summer rainfall (Wang et al. 2008; Yanai and Wu 2006). Finally, role of the adjacent ocean on the mei-yu merits further investigations. Recent studies suggest that variation of sea surface temperature over the East China Sea to the northwestern Pacific affect seasonal migration (Gan et al. 2019) and intensity (Kuwano-Yoshida et al. 2013) of the mei-yu-baiu rainband.

Acknowledgments. This work was supported by the National Science Foundation Grant AGS-1405479. The simulations in this study were conducted on the Yellowstone high-performance IBM cluster at NCAR. We thank Dr. Hisashi Nakamura and three anonymous reviewers for their careful reviews and insightful comments. We thank Leif M. Swenson for sharing codes of the SOMs, and Dr. Michael J. Herman for helpful discussions and for his constructive comments and edits on an earlier draft of this paper. WK thanks Dr. Peter H. Lauritzen for his help in the use of the NCAR Global Model Topography Generation Software. APHRODITE precipitation data were obtained from http://www.chikyu.ac.jp/precip/index.html, and we acknowledge the ECMWF for making the ERAInterim data publicly available (http://apps.ecmwf.int/ datasets/data/interim-full-moda/). Boundary topography 
Plateau control
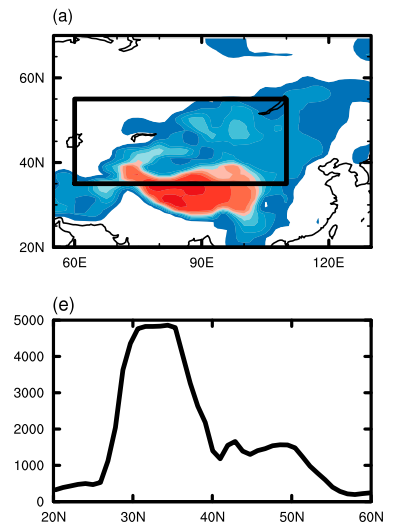

Plateau_3deg
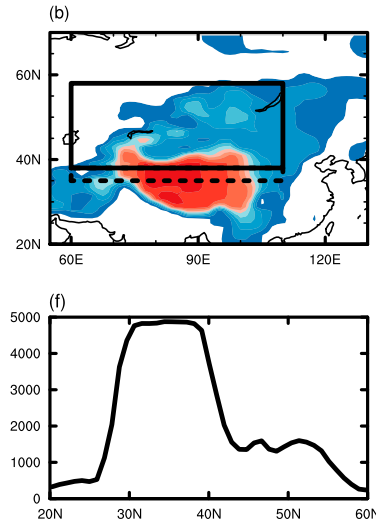

Plateau 6deg
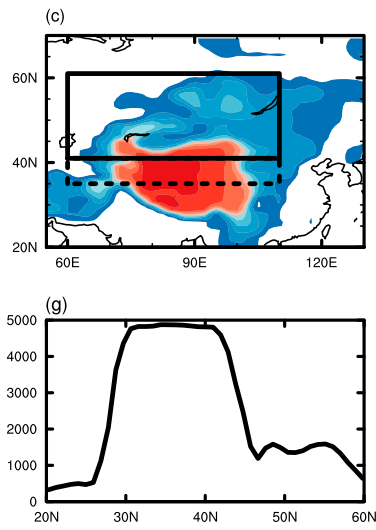

Plateau 10deg
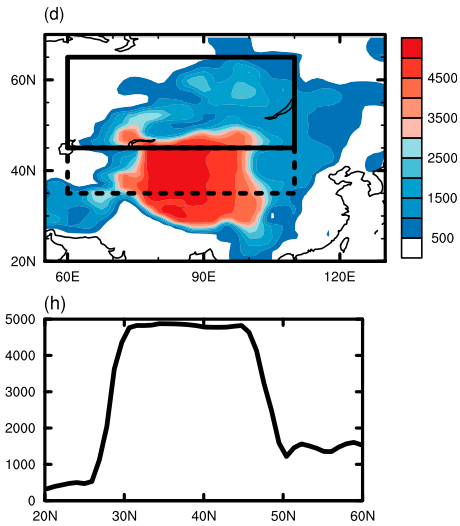

FIG. A1. Boundary topography (m) for (a),(e) the Plateau_control run and (b)-(d),(f)-(h) the extended plateau simulations. (top) The distribution of topography in East Asia, and (bottom) the vertical cross section of elevation averaged over $80^{\circ}-100^{\circ} \mathrm{E}$.

and model output for the extended plateau simulations and the dry dynamical core simulations are archived and available at https://datadryad.org/stash/ dataset/doi:10.6078/D1ZH51. Code for calculations of the three-dimensional Eliassen-Palm flux is obtained from http://www.atmos.rcast.u-tokyo.ac.jp/nishii/programs/ index.html. Calculation and visualizations are based on the National Center for Atmospheric Research Command Language (NCL) (version 6.4.0), UCAR/NCAR/CISL/ TDD, http://dx.doi.org/10.5065/D6WD3XH5.

\section{(a) EOF 1}

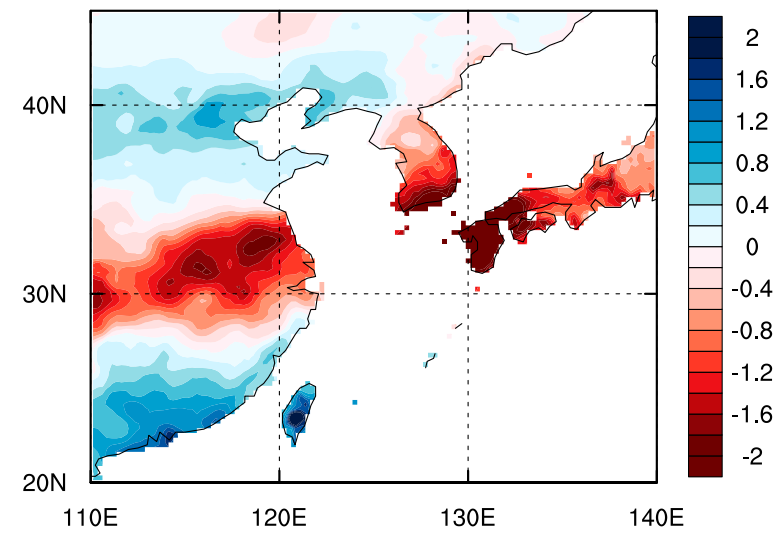

(b) PC 1

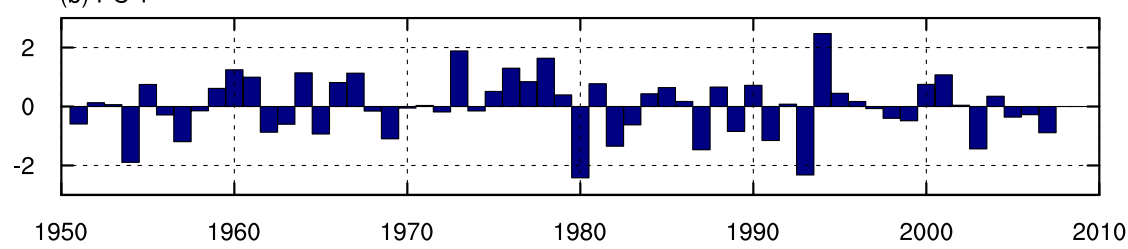

FIG. A2. The (a) first EOF and (b) principal component of July-August mean precipitation over East Asia $\left(100^{\circ}-145^{\circ} \mathrm{E}, 20^{\circ}-45^{\circ} \mathrm{N}\right)$. The spatial pattern is the regression of the normalized $\mathrm{PC} 1$ onto the July-August rainfall anomaly ( $\mathrm{mm}$ day $^{-1}$ per standard deviation). The first mode is the wellknown tripole pattern (Hsu and Lin 2007) with reduced rainfall over central eastern China and Japan and increased rainfall over northeastern and southeastern China. We use the APHRODITE dataset spanning 1951-2007. The mode explains $17.7 \%$ of the total variance. Adopted from Chiang et al. (2017) and reproduced based on Figs. 1b and 1c of Chiang et al. (2017). 


\section{APPENDIX}

\section{Topography for the Extended Plateau Simulations and the Leading EOF Mode of July-August Precipitation}

Figure A1 shows the boundary topography used in the extended plateau simulations, and Fig. A2 shows the leading EOF mode of July-August precipitation in East Asia.

\section{REFERENCES}

Baldwin, J., and G. Vecchi, 2016: Influence of the Tian Shan on arid extratropical Asia. J. Climate, 29, 5741-5762, https://doi.org/ 10.1175/JCLI-D-15-0490.1.

Bolin, B., 1950: On the influence of the earth's orography on the general character of the westerlies. Tellus, 2, 184-195, https:// doi.org/10.3402/tellusa.v2i3.8547.

Broccoli, A. J., and S. Manabe, 1992: The effects of orography on midlatitude Northern Hemisphere dry climates. J. Climate, $\mathbf{5}$, 1181-1201, https://doi.org/10.1175/1520-0442(1992)005<1181: TEOOOM $>2.0 . \mathrm{CO} ; 2$.

Chang, C.-H., and N. C. Johnson, 2015: The continuum of wintertime Southern Hemisphere atmospheric teleconnection patterns. J. Climate, 28, 9507-9529, https://doi.org/10.1175/JCLI-D14-00739.1.

Charney, J. G., and A. Eliassen, 1949: A numerical method for predicting the perturbations of the middle latitude westerlies. Tellus, 1, 38-54, https://doi.org/10.3402/tellusa.v1i2.8500.

Chattopadhyay, R., A. K. Sahai, and B. N. Goswami, 2008: Objective identification of nonlinear convectively coupled phases of monsoon intraseasonal oscillation: Implications for prediction. J. Atmos. Sci., 65, 1549-1569, https://doi.org/10.1175/ 2007JAS2474.1.

Chen, J., and S. Bordoni, 2014: Orographic effects of the Tibetan Plateau on the East Asian summer monsoon: An energetic perspective. J. Climate, 27, 3052-3072, https://doi.org/10.1175/ JCLI-D-13-00479.1.

— and _ 2016: Early summer response of the East Asian summer monsoon to atmospheric $\mathrm{CO}_{2}$ forcing and subsequent sea surface warming. J. Climate, 29, 5431-5446, https://doi.org/ 10.1175/JCLI-D-15-0649.1.

Chen, T.-J. G., and C.-P. Chang, 1980: The structure and vorticity budget of an early summer monsoon trough (mei-yu) over southeastern China and Japan. Mon. Wea. Rev., 108, 942-953, https://doi.org/10.1175/1520-0493(1980)108<0942: TSAVBO $>2.0 . \mathrm{CO} ; 2$.

Chiang, J. C. H., and Coauthors, 2015: Role of seasonal transitions and westerly jets in East Asian paleoclimate. Quat. Sci. Rev. 108, 111-129, https://doi.org/10.1016/j.quascirev.2014.11.009.

—, L. M. Swenson, and W. Kong, 2017: Role of seasonal transitions and the westerlies in the interannual variability of the East Asian summer monsoon precipitation. Geophys. Res. Lett., 44, 3788-3795, https://doi.org/10.1002/2017GL072739.

Chou, C., and J. D. Neelin, 2003: Mechanisms limiting the northward extent of the northern summer monsoons over North America, Asia, and Africa. J. Climate, 16, 406-425, https://doi.org/10.1175/ 1520-0442(2003)016<0406:MLTNEO > 2.0.CO;2.

Chu, J.-E., S. N. Hameed, and K.-J. Ha, 2012: Nonlinear, intraseasonal phases of the East Asian summer monsoon: Extrac- tion and analysis using self-organizing maps. J. Climate, 25, 6975-6988, https://doi.org/10.1175/JCLI-D-11-00512.1.

Cook, K. H., and I. M. Held, 1992: The stationary response to largescale orography in a general circulation model and a linear model. J. Atmos. Sci., 49, 525-539, https://doi.org/10.1175/ 1520-0469(1992)049<0525:TSRTLS >2.0.CO;2.

Day, J. A., I. Fung, and W. Liu, 2018: Changing character of rainfall in eastern China, 1951-2007. Proc. Natl. Acad. Sci. USA, 115, 2016-2021, https://doi.org/10.1073/PNAS.1715386115.

Dee, D. P., and Coauthors, 2011: The ERA-Interim reanalysis: Configuration and performance of the data assimilation system. Quart. J. Roy. Meteor. Soc., 137, 553-597, https://doi.org/ 10.1002/qj.828.

Ding, Y., 1992: Summer monsoon rainfalls in China. J. Meteor. Soc. Japan, 70, 373-396, https://doi.org/10.2151/jmsj1965.70.1B_373.

— , and J. C. L. Chan, 2005: The East Asian summer monsoon: An overview. Meteor. Atmos. Phys., 89, 117-142, https://doi. org/10.1007/s00703-005-0125-z.

Enomoto, T., B. J. Hoskins, and Y. Matsuda, 2003: The formation mechanism of the Bonin high in August. Quart. J. Roy. Meteor. Soc., 129, 157-178, https://doi.org/10.1256/qj.01.211.

Flohn, H., 1957: Large-scale aspects of the "summer monsoon" in South and East Asia. J. Meteor. Soc. Japan, 35A, 180-186, https://doi.org/10.2151/jmsj1923.35A.0_180.

Gan, B., Y.-O. Kwon, T. M. Joyce, K. Chen, and L. Wu, 2019: Influence of the Kuroshio interannual variability on the summertime precipitation over the East China Sea and adjacent area. J. Climate, 32, 2185-2205, https://doi.org/10.1175/JCLID-18-0538.1.

Hahn, D. G., and S. Manabe, 1975: The role of mountains in the South Asian monsoon circulation. J. Atmos. Sci., 32, 15151541, https://doi.org/10.1175/1520-0469(1975)032<1515: TROMIT>2.0.CO;2.

Held, I. M., 1983: Stationary and quasi-stationary eddies in the extratropical troposphere: Theory. Large-Scale Dynamical Processes in the Atmosphere, B. Hoskins and R. P. Pearce, Eds., Academic Press, 127-168.

and M. J. Suarez, 1994: A proposal for the intercomparison of the dynamical cores of atmospheric general circulation models. Bull. Amer. Meteor. Soc., 75, 1825-1830, https://doi.org/10.1175/ 1520-0477(1994)075<1825:APFTIO > 2.0.CO;2.

Hong, X., and R. Lu, 2016: The meridional displacement of the summer Asian jet, Silk Road pattern, and tropical SST anomalies. J. Climate, 29, 3753-3766, https://doi.org/10.1175/ JCLI-D-15-0541.1.

- _ - and S. Li, 2018: Asymmetric relationship between the meridional displacement of the Asian westerly jet and the Silk Road pattern. Adv. Atmos. Sci., 35, 389-396, https://doi.org/ 10.1007/S00376-017-6320-2.

Hoskins, B. J., and D. J. Karoly, 1981: The steady linear response of a spherical atmosphere to thermal and orographic forcing. J. Atmos. Sci., 38, 1179-1196, https://doi.org/10.1175/15200469(1981)038<1179:TSLROA > 2.0.CO;2.

Hsu, H.-H., and S.-M. Lin, 2007: Asymmetry of the tripole rainfall pattern during the East Asian summer. J. Climate, 20, 44434458, https://doi.org/10.1175/JCLI4246.1.

Huang, D.-Q., J. Zhu, Y.-C. Zhang, and A.-N. Huang, 2014: The different configurations of the East Asian polar front jet and subtropical jet and the associated rainfall anomalies over eastern China in summer. J. Climate, 27, 8205-8220, https:// doi.org/10.1175/JCLI-D-14-00067.1.

Hurrell, J. W., J. J. Hack, D. Shea, J. M. Caron, and J. Rosinski, 2008: A new sea surface temperature and sea ice boundary 
dataset for the Community Atmosphere Model. J. Climate, 21, 5145-5153, https://doi.org/10.1175/2008JCLI2292.1.

— , and Coauthors, 2013: The Community Earth System Model: A framework for collaborative research. Bull. Amer. Meteor. Soc., 94, 1339-1360, https://doi.org/10.1175/BAMS-D-1200121.1.

Johnson, N. C., 2013: How many ENSO flavors can we distinguish? J. Climate, 26, 4816-4827, https://doi.org/10.1175/JCLI-D-1200649.1.

- , S. B. Feldstein, and B. Tremblay, 2008: The continuum of Northern Hemisphere teleconnection patterns and a description of the NAO shift with the use of self-organizing maps. J. Climate, 21, 6354-6371, https://doi.org/10.1175/2008JCLI2380.1.

Kitoh, A., 2004: Effects of mountain uplift on East Asian summer climate investigated by a coupled atmosphere-ocean GCM. J. Climate, 17, 783-802, https://doi.org/10.1175/15200442(2004)017<0783:EOMUOE >2.0.CO;2.

Kohonen, T., 2001: Self-Organizing Maps. 3rd ed. Springer, 501 pp.

— J. J. Hynninen, J. Kangas, and J. Laaksonen, 1996: SOM_PAK: The self-organizing maps program package. Helsinki University of Technology, Faculty of Information Technology, Laboratory of Computer and Information Science, Rep. A31, 25 pp.

Kong, W., L. M. Swenson, and J. C. H. Chiang, 2017: Seasonal transitions and the westerly jet in the Holocene East Asian summer monsoon. J. Climate, 30, 3343-3365, https://doi.org/ 10.1175/JCLI-D-16-0087.1.

Kosaka, Y., S.-P. Xie, and H. Nakamura, 2011: Dynamics of interannual variability in summer precipitation over East Asia. J. Climate, 24, 5435-5453, https://doi.org/10.1175/2011JCLI4099.1.

Kuwano-Yoshida, A., B. Taguchi, and S.-P. Xie, 2013: Baiu rainband termination in atmospheric and coupled atmosphereocean models. J. Climate, 26, 10111-10124, https://doi.org/ 10.1175/JCLI-D-13-00231.1.

Lauritzen, P. H., J. T. Bacmeister, P. F. Callaghan, and M. A. Taylor, 2015: NCAR global model topography generation software for unstructured grids. Geosci. Model Dev., 8, 39753986, https://doi.org/10.5194/gmd-8-3975-2015.

Li, C., and M. Yanai, 1996: The onset and interannual variability of the Asian summer monsoon in relation to land-sea thermal contrast. J. Climate, 9, 358-375, https://doi.org/10.1175/15200442(1996)009<0358:TOAIVO > 2.0.CO;2.

Li, L., and Y. Zhang, 2014: Effects of different configurations of the East Asian subtropical and polar front jets on precipitation during the mei-yu season. J. Climate, 27, 6660-6672, https:// doi.org/10.1175/JCLI-D-14-00021.1.

Li, X., and R. Lu, 2017: Extratropical factors affecting the variability in summer precipitation over the Yangtze River Basin, China. J. Climate, 30, 8357-8374, https://doi.org/10.1175/JCLID-16-0282.1.

Liang, X.-Z., and W.-C. Wang, 1998: Associations between China monsoon rainfall and tropospheric jets. Quart. J. Roy. Meteor. Soc., 124, 2597-2623, https://doi.org/10.1002/qj.49712455204.

Lutsko, N. J., and I. M. Held, 2016: The response of an idealized atmosphere to orographic forcing: Zonal versus meridional propagation. J. Atmos. Sci., 73, 3701-3718, https://doi.org/ 10.1175/JAS-D-16-0021.1.

Manabe, S., and T. B. Terpstra, 1974: The effects of mountains on the general circulation of the atmosphere as identified by numerical experiments. J. Atmos. Sci., 31, 3-42, https://doi.org/ 10.1175/1520-0469(1974)031<0003:TEOMOT>2.0.CO;2.

Molnar, P., W. R. Boos, and D. S. Battisti, 2010: Orographic controls on climate and paleoclimate of Asia: Thermal and mechanical roles for the Tibetan Plateau. Annu. Rev. Earth
Planet. Sci., 38, 77-102, https://doi.org/10.1146/annurev-earth040809-152456.

Murakami, T., 1951: On the study of the change of the upper westerlies in the last stage of baiu season (rainy season in Japan). J. Meteor. Soc. Japan, 29, 162-175, https://doi.org/10.2151/ jmsj1923.29.5_162.

Neale, R. B., and Coauthors, 2010: Description of the NCAR Community Atmosphere Model (CAM 5.0). NCAR Tech. Note NCAR/TN-486+STR, 268 pp., www.cesm.ucar.edu/ models/cesm1.1/cam/docs/description/cam5_desc.pdf.

Ninomiya, K., 1984: Characteristics of Baiu front as a predominant subtropical front in the summer Northern Hemisphere. J. Meteor. Soc. Japan, 62, 880-894, https://doi.org/10.2151/jmsj1965.62.6_880.

_ 2000: Large- and meso- $\alpha$-scale characteristics of meiyu/baiu front associated with intense rainfalls in 1-10 July 1991. J. Meteor. Soc. Japan, 78, 141-157, https://doi.org/10.2151/ jmsj1965.78.2_141.

_ , and Y. Shibagaki, 2007: Multi-scale features of the meiyubaiu front and associated precipitation systems. J. Meteor. Soc. Japan, 85B, 103-122, https://doi.org/10.2151/jmsj.85B.103.

Park, H.-S., J. C. H. Chiang, and S. Bordoni, 2012: The mechanical impact of the Tibetan Plateau on the seasonal evolution of the South Asian monsoon. J. Climate, 25, 2394-2407, https:// doi.org/10.1175/JCLI-D-11-00281.1.

Plumb, R. A., 1985: On the three-dimensional propagation of stationary waves. J. Atmos. Sci., 42, 217-229, https://doi.org/ 10.1175/1520-0469(1985)042<0217:OTTDPO > 2.0.CO;2.

Rodwell, M. J., and B. J. Hoskins, 2001: Subtropical anticyclones and summer monsoons. J. Climate, 14, 3192-3211, https://doi.org/ 10.1175/1520-0442(2001)014<3192:SAASM >2.0.CO;2.

Sampe, T., and S.-P. Xie, 2010: Large-scale dynamics of the meiyubaiu rainband: Environmental forcing by the westerly jet. J. Climate, 23, 113-134, https://doi.org/10.1175/2009JCLI3128.1.

Schiemann, R., D. Lüthi, and C. Schär, 2009: Seasonality and interannual variability of the westerly jet in the Tibetan Plateau region. J. Climate, 22, 2940-2957, https://doi.org/10.1175/ 2008JCLI2625.1.

Seager, R., and N. Henderson, 2013: Diagnostic computation of moisture budgets in the ERA-Interim reanalysis with reference to analysis of CMIP-archived atmospheric model data. J. Climate, 26, 7876-7901, https://doi.org/10.1175/JCLI-D-1300018.1

Seo, K.-H., J.-H. Son, J.-Y. Lee, and H.-S. Park, 2015: Northern East Asian monsoon precipitation revealed by airmass variability and its prediction. J. Climate, 28, 6221-6233, https:// doi.org/10.1175/JCLI-D-14-00526.1.

Shaw, T. A., and O. Pauluis, 2012: Tropical and subtropical meridional latent heat transports by disturbances to the zonal mean and their role in the general circulation. J. Atmos. Sci. 69, 1872-1889, https://doi.org/10.1175/JAS-D-11-0236.1.

Son, J.-H., K.-H. Seo, and B. Wang, 2019: Dynamical control of the Tibetan Plateau on the East Asian summer monsoon. Geophys. Res. Lett., 46, 7672-7679, https://doi.org/10.1029/2019GL083104.

Staff Members, 1958: On the general circulation over Eastern Asia (II). Tellus, 10, 58-75, https://doi.org/10.3402/tellusa.v10i1. 9219. [The full authorship is given as "Staff Members of the Section of Synoptic and Dynamic Meteorology, Institute of Geophysics and Meteorology, Academia Sinica"; authors are not listed.]

Suzuki, S., and B. Hoskins, 2009: The large-scale circulation change at the end of the baiu season in Japan as seen in ERA40 data. J. Meteor. Soc. Japan, 87, 83-99, https://doi.org/10.2151/ jmsj.87.83. 
Takahashi, K., and D. S. Battisti, 2007: Processes controlling the mean tropical Pacific precipitation pattern. Part I: The Andes and the eastern Pacific ITCZ. J. Climate, 20, 3434-3451, https://doi.org/10.1175/JCLI4198.1.

Tang, H., A. Micheels, J. T. Eronen, B. Ahrens, and M. Fortelius, 2013: Asynchronous responses of East Asian and Indian summer monsoons to mountain uplift shown by regional climate modelling experiments. Climate Dyn., 40, 1531-1549, https://doi.org/10.1007/s00382-012-1603-x.

Tao, S., and L. Chen, 1987: A review of recent research on the East Asian summer monsoon in China. Monsoon Meteorology, C.-P. Chang and T. N. Krishnamurti, Eds., Oxford University Press, 60-92.

Tomita, T., T. Yamaura, and T. Hashimoto, 2011: Interannual variability of the baiu season near Japan evaluated from the equivalent potential temperature. J. Meteor. Soc. Japan, 89, 517-537, https://doi.org/10.2151/jmsj.2011-507.

Vertenstein, M., T. Craig, A. Middleton, D. Feddema, and C. Fischer, 2011: CESM1.0.4 User's Guide. http://www.cesm. ucar.edu/models/cesm1.0/cesm/cesm_doc_1_0_4/book1.html.

Wang, B., Q. Bao, B. J. Hoskins, and Y. Liu, 2008: Tibetan Plateau warming and precipitation changes in East Asia. Geophys. Res. Lett., 35, L14702, https://doi.org/10.1029/2008GL034330.

Wang, S., and H. Zuo, 2016: Effect of the East Asian westerly jet's intensity on summer rainfall in the Yangtze River Valley and its mechanism. J. Climate, 29, 2395-2406, https://doi.org/ 10.1175/JCLI-D-15-0259.1.

Wong, K. C., S. Liu, A. G. Turner, and R. K. Schiemann, 2018: Different Asian monsoon rainfall responses to idealized orography sensitivity experiments in the HadGEM3-GA6 and FGOALS-FAMIL global climate models. Adv. Atmos. Sci., 35, 1049-1062, https://doi.org/10.1007/s00376-018-7269-5.

Wu, G., Y. Liu, B. He, Q. Bao, A. Duan, and F.-F. Jin, 2012: Thermal controls on the Asian summer monsoon. Sci. Rep., 2, 404, https://doi.org/10.1038/srep00404.

Xie, Z., Y. Du, and S. Yang, 2015: Zonal extension and retraction of the subtropical westerly jet stream and evolution of precipitation over East Asia and the western Pacific. J. Climate, 28, 6783-6798, https://doi.org/10.1175/JCLI-D-14-00649.1.

Yanai, M., and G.-X. Wu, 2006: Effects of the Tibetan Plateau. The Asian Monsoon, B. Wang, Ed., Springer, 513-549.

Yatagai, A., O. Arakawa, K. Kamiguchi, H. Kawamoto, M. I. Nodzu, and A. Hamada, 2009: A 44-year daily gridded precipitation dataset for Asia based on a dense network of rain gauges. SOLA, 5, 137-140, https://doi.org/10.2151/sola.2009-035.

Yeh, T.-C., S.-Y. Dao, and M.-T. Li, 1959: The abrupt change of circulation over the Northern Hemisphere during June and October. The Atmosphere and the Sea in Motion, B. Bolin, Ed., Rockefeller Institute Press, 249-267.

Zhang, G. J., and N. A. McFarlane, 1995: Sensitivity of climate simulations to the parameterization of cumulus convection in the Canadian Climate Centre general circulation model. Atmos.-Ocean, 33, 407-446, https://doi.org/10.1080/07055900.1995.9649539.

Zhang, R., D. Jiang, X. Liu, and Z. Tian, 2012: Modeling the climate effects of different subregional uplifts within the HimalayaTibetan Plateau on Asian summer monsoon evolution. Chin. Sci. Bull., 57, 4617-4626, https://doi.org/10.1007/s11434-012-5284-y. 